\title{
Applying Complement Therapeutics to Rare Diseases
}

Edimara S. Reis*, Dimitrios C. Mastellos ${ }^{\dagger}$, Despina Yancopoulou ${ }^{\ddagger}$, Antonio M. Risitano ${ }^{\S}$, Daniel Ricklin* and John D. Lambris*

*Department of Pathology and Laboratory Medicine, University of Pennsylvania, Philadelphia, PA, USA

†Division of Biodiagnostic Sciences and Technologies, INRASTES, National Center for Scientific Research 'Demokritos,' Athens, Greece

‡AmyndasPharmaceuticals, Glyfada, Greece

§Hematology Department of Clinical Medicine and Surgery, Federico II University of Naples, Naples, Italy

Correspondence:

Prof. John D. Lambris, Department of Pathology \& Laboratory Medicine, University of Pennsylvania, 401 Stellar Chance, 422 Curie Blvd., Philadelphia, PA, 19104, USA. Phone: 215746-5765, FAX: 215-573-8738, E-mail: lambris@upenn.edu 


\begin{abstract}
Around 350 million people worldwide suffer from rare diseases. These may have a genetic, infectious, or autoimmune basis, and several include an inflammatory component. Launching of effective treatments can be very challenging when there is a low disease prevalenceand limited scientific insightsinto the disease mechanisms. As a key trigger of inflammatory processes, complement has been associated with a variety of diseases and has become anattractive therapeutic target for conditions involving inflammation.In view of the clinical experience acquired with drugs licensedfor the treatment of rare diseases such as hereditary angioedema and paroxysmal nocturnal hemoglobinuria, growing evidence supports the safety and efficacy of complement therapeutics in restoring immune balance and preventing aggravation of clinical outcomes. This review provides an overview of the candidates currently in the pharmaceutical pipeline withpotential to treat orphan diseases and discusses the molecular mechanisms triggered by complement involved withthe disease pathogenesis.
\end{abstract}

Keywords:autoimmune diseases, C1inhibitor, complement, compstatin, eculizumab, orphan drugs, rare diseases. 


\section{List of Abbreviations:}

AChR- acetylcholine receptor

aHUS-atypical hemolytic uremic syndrome

AMD- age-related macular degeneration

AMR- antibody-mediated rejection

ANCA- anti-neutrophil cytoplasmic antibody

AP- alternative pathway

C1-INH- C1 esterase Inhibitor

C3GN- C3 glomerulonephritis

C5aR- C5a receptor

C4BP- C4b binding protein

CAD- cold agglutinin disease

CCP- complement control protein domains

CP- classical pathway

CRIg- complement receptor of the immunoglobulin superfamily

DAF- decay accelerating factor

DDD- dense deposit disease

EMA- Europeanmedicine agency

FB- Factor B

FD- Factor D

FDA- Food and Drug Administration 
FH- Factor $\mathrm{H}$

FI- Factor I

GA- geographic atrophy

GBS- Guillain-Barrésyndrome

GPCR- G-protein-coupled receptor

GPI- glycosyl-phosphatidyl-inositol

HAE- hereditary angioedema

HLA- human leukocyte antigen

HUS- hemolytic uremic syndrome

IRI- ischemia-reperfusion injury

IVIG- intravenous immunoglobulin

LRP- low density lipoprotein receptor-related protein

LP- lectin pathway

MAC- membrane attack complex

MASP- MBL-associated serine protease

MBL- mannose-binding lectin

MCP- membrane cofactor protein

MG- myasthenia gravis

MMN- multifocal motor neuropathy

MuSK- muscle-specific receptor tyrosine kinase

NMO- neuromyelitisoptica 
PIG-A- phosphatidyl-inositol glycan class A

PNH- paroxysmal nocturnal hemoglobinuria

RBC- red blood cells

RGD- arginine-glycine-aspartic acid

SERPIN- serine protease inhibitor

STEC- shiga toxin-producing Escherichia coli

TMA- thrombotic microangiopathy

TTP- thrombotic thrombocytopenic purpura 


\section{Introduction}

The complement system is invariably considered one of the most ancient defense mechanisms of the body[1]. Since the discovery of the bactericidal properties of serum components more than a century ago,the perception of complement as part of immunity has changed considerably [2]. Initially regarded as a mere co-adjuvant in microbial elimination through opsonization and lysis, it is hard to assume that evolutionary forces would conserve such an intricate system comprising about 50 proteins to act entirely on microbial killing.Today, complement is seen not only as a first line of defense against pathogens but also as a modulator of acquired immunity, being the decisive factor that guides the quality and magnitude of cell activation and also orchestrates several important physiological and pathologicalprocesses, such as the clearance of foreign bodies, coagulation, tissue regeneration, and inflammation (Fig. 1) [2-4].

The biological functions of complement are elicitedas a result of the activation of the classical, alternative,and/or lectin pathways (CP, AP, and LP, respectively). The initial components of each pathway serve as pattern recognition molecules: C1q fixesantigen-antibody complexes,mannose binding lectins (MBL) and ficolins bind to microbial carbohydrates, and molecules of C3b and properdin recognize self- and non-self-structures that are damaged or lack complement-regulatory proteins. The initial trigger for the CP and LP leads to subsequent activation of the components C2 and C4 and the formation of the C3convertase, C4b2b (Fig. 2). The AP is continuously activated via the spontaneous hydrolysis of C3,resultingin a conformational change that allows the binding of Factor B (FB). Upon cleavage of FB by the serineprotease factor D (FD), the C3bBb complex is formed. This complex acts as the C3convertase of the AP and plays a critical role in the amplification of the AP as a result of the continuousproduction of C3b molecules (Fig. 2),ensuringan immediate and effective response against danger signals. More recently, properdin has been identified as a pattern recognition molecule that is able to initiate the activation of the AP[5]. In addition, it also acts as a positive regulator of the $\mathrm{C} 3 \mathrm{bBb}$ complex, favoring stable and longer activation of the AP. All three pathways converge at the cleavage of $\mathrm{C} 3$ by one of the C3convertases, togenerate the fragments C3a and C3b. C5 is similarly activated by C5convertases (C4b2b3b or C3bBb3b) to produce the fragments C5a, an important inducer of inflammation, and C5b, the initial component of the terminal complement pathway (Fig. 2). The protein fragments produced during this activation 
cascade can either play a role in further activating the system and/or binding to specific receptors on cell surfaces to induce a functional response. The complement cascade culminates in the formation of the membrane attack complex (MAC: C5bC6C7C8C9 $)$ (2, 6]. In sublytic amounts, particularly on nucleated cells, the MACsignificantly affects cell signaling pathways and promotes inflammation [7]. Furthermore, as has been long appreciated, it promotes the osmotic lysis of microbes and of cells lacking proper complement regulation.

An essential aspect of complement'sprecise operation is thetight regulation of distinct stages of the system. This regulatory task is carried out by several soluble and cell surfaceexpressed proteins (Fig. 2).The soluble regulators are C1inhibitor (C1-INH),Factor I (FI),Factor $\mathrm{H}(\mathrm{FH})$, and $\mathrm{C} 4 \mathrm{~b}$ binding protein (C4BP); the regulatory cell receptors are complement receptor type 1 (CR1 or CD35),membrane cofactor protein (MCP or CD46),decay accelerator factor (DAF or CD55), and CD59[2, 8].A proper level of regulation prevents uncontrolled activation and amplification of the system and assuresthe preservation of host cells and tissues while a destructiveresponse is being mounted against the 'intruder'. In fact,in addition to the presence of a defective complement component oran excessive trigger signal, insufficient regulation is often recognized as a pathogenic driver of complement-related diseases.Indeed, many inflammatory, autoimmune, and infectious diseases have been associated with exacerbated complement activity[9, 10]. More specifically, the discovery of the molecular mechanisms underlying the pathology in dense deposit disease (DDD), paroxysmal nocturnal hemoglobinuria (PNH), atypical hemolytic uremic syndrome (aHUS), and age-related macular degeneration (AMD) hasrevitalized interest in unveiling the mechanisms that drive extreme complement activation in disease. It has also propelled efforts to develop novel strategies fortargeting complement activationwith the goal of interfering with the disease course.

Influenced by the clinical success of the anti-C5 antibody eculizumabin the treatment of PNH and aHUS, twoorphan diseases characterized by an overactive complement system, an array of drugs designed to modulate complement activity is currently in the pharmaceutical pipeline, with thegoal of treating rare diseases. In fact, since the implementation of the Orphan Drug Act in 1983, about 400 new drugs have been approved by the Food and Drug Administration (FDA) for rare diseases. In view of the existence of approximately 7,000 different types of rare disease (defined as affecting fewer than 200,000 people in the US) 
affecting 350 million people worldwide, the introduction of novel therapeutic compounds that could prevent, delay, or even halt the progression of these diseases is highly anticipated by both the medical and patient communities. Here we provide an overview of drug candidates that interfere with complement activation and are currently in clinical development for the treatment of rare diseases.

\section{Targeting the Complement System: Where, When, and How Much}

Given its upstream position in inflammatory and immunomodulatory processes and the immunological basis of a number of diseases, blockade of complement-mediated functions has long been pursuedas a valid therapeutic option[9]. With various potential sites of inhibition to be considered (Fig. 2 and 3), the chosen therapy should reflect a consideration of the pathological mechanisms of the disease, such as the trigger of complement activation, the pathway(s) involved, the location of the complement activation, and the disease course. It is unlikely that the optimal target for a particular pathology will be suited for several distinct classes of disease;furthermore, some conditions may require combined inhibition of two or even all three complement pathways. Also, the delivery route and the point and extent of the inhibition must be carefully defined for each specific indication. Finally, a careful evaluation of adverse effects includingdrug-related impairment of complement-mediated defense mechanisms should be performed (Fig. 3). Ideally, the optimal therapy should be sufficient to constrain exacerbated complement activation without shutting down necessary biological functions pertinent to immune surveillance or tissue homeostasis. The available data from clinical trials with distinct

drug candidates have not yet raised any safety concerns; however, definitive answers to the very relevant questions addressed here will only come after extensive clinical experience has been gained. Some of these issueswill be further considered below.

\section{Targeting the Initiators}

\subsection{C1Inhibitor}

C1-INH is a soluble, highly glycosylated serine protease inhibitor of $110 \mathrm{kDa}$ that circulates with a concentration of $\sim 0.2 \mathrm{mg} / \mathrm{ml}$. Its main function is to control the various proteases involved in 
the complement, kinin, fibrinolytic, and coagulation systems [11] (Fig. 3). Despite its broader target specificity, preparations of C1-INH are the only complement protease inhibitor currently available in the clinicwith a primary indication for the treatment of HAE. However, given the safe and successful outcomes that have been achieved in HAE therapy, C1-INH is now being investigated in trials for several disease states such as sepsis (NCT01766414, NCT00785018, 2011-002222-46), transplant rejection (NCT01134515, NCT01147302), neuromyelitisoptica (NMO) (NCT01759602), ischemia-reperfusion injury (IRI) (NCT01886443), and autoimmune hemolytic anemia (2012-003710-13).Four different C1-INH concentrates have been approved by the FDA and European medicine agency (EMA). They are: Berinert (CSL Behring), Cetor(Sanquin), and Cinryze (ViroPharma Biologics) and the recombinant C1-INH concentrate Ruconest (Pharming Group N.V)(Tables 1 and 2).

Berinertwas accorded orphan drug status by the FDA in 1992 (Table 1) and is now marketed in several countries. The active drug consists of purified C1-INH from human plasma.In addition to HAE, Berinert is currently being tested for the prevention of antibodymediated rejection in human leukocyte antigen (HLA)-sensitized patients. A phase I/II clinical trial completed at the end of 2014 demonstrated that the use of C1-INH is safe in the posttransplant period and may reduce the risk of ischemia-reperfusion injury (IRI) [12].

Like Berinert, C1-INH from human plasma is also the active substance in Cetor[13] and Cinryze. Cinryze, but not Cetor,has held orphan drug status from the FDA for HAE since 2004 (Tables 1 and 2) and has also been tested as an add-on therapy for NMO. Aproof-of-concept trial carried out in 10 patients with NMOhas demonstrated the safety of C1-INH and promises benefits regarding neurological damage in NMO [14].

In contrast to the compounds described above, Ruconest is a recombinant human protein purified from the milk of transgenic rabbits that has recently been approved by the FDA for acute attacks of HAE. While a lower degree of glycosylation accounts for the shorter half-life of Ruconest (1.6 h vs. $>30 \mathrm{~h}$ for Berinert, Cetor, and Cinryze) this distinct feature does not have an obvious effect on its clinical efficacy $[15,16]$. Along with the FDA approval as an orphan drug for the treatment of HAE (Table 1), it has also been designated for the prevention and treatment of delayed graft function after solid organ transplantation (Table 1); however, the related clinical trial was withdrawn in 2012 (NCT01035593) with the claim that recent improvements in clinical practice have reduced the apparent incidence of antibody-mediated rejection in renal 
transplantation. Ruconest has also been designated for the treatment of capillary leakage syndrome, a rare and life-threatening condition characterized by episodes of severe hypotension, hypoalbuminemia, and hemoconcentrationthat develop as a complication of diseases states such as bone marrow/stem cell transplantation, IL-2 therapy, sepsis, and neonatal cardiac surgery; however, no relevant advances or clinical trials have yet been announced by Pharming.

A fifth C1-INH compound, developed by Alpha Therapeutic Corporation, has also received FDA orphan status for the treatment of HAE. No further developmentswere announced after the company was acquired by Grifols in 2003. While substitution therapy with C1-INH is certainly the most effective treatment for HAE, its elevated costs and laborious production may limit its application for other diseases. However, although the impact is still difficult to evaluate, it is expected that the introduction of Ruconest into the clinic may reduce the therapy costs for HAE.

\section{Hereditary Angioedema}

HAE,a potentially life-threatening disease that affects approximately 1:50,000 people worldwide, is associated with an inherited deficiency of C1-INH[17]. HAE can present as low levels of protein (type I) or the production of a dysfunctional protein (type II). HAE type III seems to be independent of C1-INH, and its etiology is still unknown. The disease is characterized by severe episodes of edema in the skin and mucosa that can be extremely debilitating, particularly if the airways are affected. The symptoms are caused by the leakage of fluids from the capillaries as a result of uncontrolled activation of the plasma cascade systems and generation of vasoactive peptides, especially bradykinin [18]. Given its chronic presentation, the disease carries a substantial socio-economic burden,with costs per patient reaching as high asUS $\$ 230,000$ annually [19].Among the treatment options for HAE, which include androgens, kallikrein inhibitors, bradykinin receptor antagonists, and human C1-INH concentrate, only C1-INH directly targets the fundamental cause of HAE and has been shown to effectively treat and prevent HAE types I and II [18]. Several clinical trials have demonstrated the safety and efficacy of all four C1-INH preparations and have indicated that a threshold baseline level of $0.38 \mathrm{U} / \mathrm{ml}$ of the protein is sufficient to protect against HAE attacks [15]. 


\subsection{Anti-C1s Antibody}

$\mathrm{C} 1 \mathrm{~s}$ is an83-kDa serine protease within the C1complex, the initiator of the CP. Itcirculatesat a concentration of $0.05 \mathrm{mg} / \mathrm{ml}$ as a proenzyme and in complex with C1q, C1r and C1-INH and is critical for the cleavage of the C4 protein, allowing for subsequent activation of the CP (Fig. 2). Deficiency states of this protease are associated with increased susceptibility to infections and autoimmune diseases [20].Thus far, the clinical experience acquired with the inhibition of complement proteases comes from Nafamostat (FUT-175), currently marketed for pancreatitis in Japan and Korea. However, like C1-INH, Nafamostat inhibits proteases other than C1s, and it is not clear whether its clinical effects are actually derived from complement inhibition [21]. No clinical trials have yet been conducted with a selective strategy for targeting a single initiator of the CP. Although this concept sounds like an interesting approach for diseases resulting from an imbalanced CP, since it leaves the other pathways free to act if required (Fig. 3), it is still not clear whether the disruption of a single pathway is sufficient to alleviate clinical signs. In line with this concept of inhibiting a single pathway, True North Therapeutics has a clinical development program for an humanized anti-C1s antibody (TNT009) for the treatment of cold agglutinin disease (CAD) (Table 2).

\section{Cold Agglutinin Disease}

CAD is a type of autoimmune hemolytic anemia in which autoantibodies (cold agglutinins) bind to red blood cells (RBC) at low temperatures to cause RBC agglutination. Anemia occurs as a result of autoantibody-mediated CP activation on thesurface of the RBCs, leading to the deposition of complement opsonins that driveextravascular hemolysis in the liver. Theannual incidence of CAD is estimated to be between 1/35,000-1/80,000 in North America and Western Europe.The most common symptoms include severe pain in the back and legs, headache, vomiting, diarrhea, dark urine, and hepatosplenomegaly. CAD can be primary (idiopathic) or secondary, caused by an underlying condition, such as infection (Mycoplasma pneumoniae), a lymphoproliferative disorder, systemic autoimmunity, or neoplasm[22]. Mild cases are usually managed non-pharmacologically, i.e., by avoiding cold exposure. In an attempt to treat more 
severe cases, corticosteroids, alkylating agents, purine nucleoside analogs, and Rituximab have been tested; however, the reported success rate is always below 50\% [23].

A recent report has shown thatTNT003 (the non-humanized form of TNT009) can prevent cold agglutinin-mediated deposition of C3 fragments onto RBCs and consequent phagocytosis of these opsonized cellsin vitro[24]. Furthermore, TNT003 also halted the production of anaphylatoxins, supporting further development of the anti-C1s antibody for use in treating autoimmune hemolytic anemia. TNT009 is the lead drug candidate of True North Therapeutics, and the company is recruiting healthy volunteers and CAD patients to test the safety and tolerability of TNT009. Indeed, it is reasonable to expect that anti-C1s blockage may clinically prevent extravascular and intravascular hemolysis mediated by C3 and the MAC. Because complement activation on RBCs is a typical aspect of antibody-mediated anemias, positive and safe results from this trial could lead to broader application of the anti-C1s antibody.

\subsection{Anti-MASP-2 Antibody}

The MBL-associated serineprotease (MASP)-2, of $\sim 80 \mathrm{kDa}$, has a concentration of $\sim 0.3 \mu \mathrm{g} / \mathrm{ml}$ in the plasma. Like C1s, it activates C2 and C4 upon binding ofMBL and ficolins to carbohydrates[25] (Fig. 2). MASP-2 deficiency has been described in 10 individuals, most of whom are healthy [26]. In contrast, one case reportgiving more detail has described an individual with increased susceptibility to infections and severe inflammatory conditions [27], indicating that the impact of MASP-2 on pathophysiological mechanisms remains elusive.

Omeros Corporation holds exclusive rights to therapeutic antibodies targeting MASP-2, and the antibody OMS721 (Table 1 and Fig. 3) has received orphan drug designation for the treatment of thrombotic microangiopathy (TMA).

\section{Thrombotic Microangiopathy}

The term TMA refers to a group of pathologies that presentwith endothelial injury and thrombosis in the capillaries and arterioles and may be associated with thrombocytopenia, anemia, purpura, and renal failure.The classic TMAs are HUS and thrombotic thrombocytopenic purpura (TTP). HUS also represents a group of pathologies with similar clinical presentations 
that are triggered by environmental or genetic factors and have an incidence of $1 / 100,000$. The typical HUS, or STEC-HUS, which accounts for $90 \%$ of all cases of HUS, is associated with infection with one of theEscherichia coli strains, which produce Shiga toxin [28]. This type of toxin targets the globotriaosylceramide receptor (Gb3), which is highly expressed by the renal microvascular endothelium and inhibits protein synthesis, causing cell death [29]. In contrast to shiga toxin-producing Escheria coli (STEC)-HUS, atypical HUS (aHUS) results from abnormalities in the control mechanisms of the complement system. More than 100 different mutations have been described in the proteins that regulate complement activation such as FH, MCP, and FI. The proteins C3 and FB have also been implicated in the pathogenesis of aHUS, as well as anti-FH antibodies [28]. TTP, in contrast, is caused by the decreased activity of ADAMTS13, a metalloprotease involved in the cleavage of the von Willebrand factor. In the acquired form of the disease, complement-activating anti-ADAMTS13 antibodies may be responsible for the pathology[30]. The annual incidence of TTP ranges from 1/250,000 to 1/1,000,000. In addition, TMA can be triggered by conditions such as pregnancy, transplantation, and metabolic and autoimmune diseases [31].Complement dysregulation is considered to be a common factor among TMA diseases and leads to endothelial damage, microvascular thrombosis, and organ damage.

An anti-MASP-2 antibody,OMS721 (Omeros Corporation), is currently being tested for safety and tolerability in phase II trials (NCT02222545 and 2014-001032-11) in TMA patients. OMS721 has received orphan drug designation from the FDA for the prevention of complementmediated TMAs. Successful trial results are highly anticipated and may validate a role for the lectin pathway in disease pathogenesis that is not yet fully comprehended by the scientific community[32]. In addition, the complement C5 inhibitor eculizumab has been shown to be efficient in the treatment of aHUS, and in some circumstances also in the treatment of HUS and TTP. In fact, eculizumab has been approved by the FDA and EMA for the treatment of aHUS, based on favorable results from separate trials that have demonstrated hematologic normalization, improvement in renal function, and a decrease in thrombotic events[33]. 


\section{Targeting the Amplification Process}

\subsection{Factor D Inhibitors}

Complement FD is a serine protease of 24 kDawith plasma concentrations of $\sim 2 \mu \mathrm{g} / \mathrm{ml}$, the lowest of all the AP proteins. Given its low concentration, FD is the limiting enzyme for AP activation, being essential for the correct operation of the AP via the activation of FB [34]; therefore, FD blockade is an effective strategy for controlling AP-mediated activation and amplification (Fig. 2 and 3). Cases of FD deficiency have previously been associated with Neisseria infections, and elevated levels of FD have been correlated with numerous disease states[35, 36].

In age-related macular degeneration (AMD), in particular, an increase in the levels of FD has been detected [37], both locally in the eye and systemically, suggesting a potential role forthe AP in the pathogenesis of AMD. In support of this concept, Genentech has developed an antiFDantibody (Lampalizumab) that is currently in phase III trials for the treatment of geographic atrophy (GA), a late-stage form of dry AMD (Table 2). Mechanistically, Lampalizumab binds to a FD site that is essential for the bindingof FD with the C3bB proconvertase[38].Although they are still in the preclinical development phase, a series of small molecules with the ability to inhibit FD have been announced byAchillion Pharmaceuticals (Table 2). The lead compound has shown sub-nanomolar inhibitory potency in in vitro studies,and although used in very high concentrations (100 mg/kg) it was able to abrogate AP activation in non-human primates for more than $24 \mathrm{~h}$ after oral administration [39].

\section{Age-related Macular Degeneration}

AMD is a late-onset, neurodegenerative disease of the eye that is characterized by progressive degeneration of the macular region of the retina, which results in progressive and irreversible vision loss[40]. AMD is the major cause of blindness in adults over 50 years of age in developed countries;although not a rare disease, it has a tight connection with complement imbalance and the unfolding of the pathology mechanisms has led to increased interest in the development of complement-related therapeutics. It is associated with the progressive deposition of 
drusen(extracellular debris) in the eye and the consequent death of the retinal pigment epithelial cells (geographic atrophy [GA;dry AMD]) and/or choroidal neovascularization leading to hemorrhage and exudation within the macula (wet AMD); in both cases,vision loss is the ultimate result. In addition to age and smoking, genetic variation in complement genes (FH, C2/BF, C3, and FI) has been implicated as a risk factor [40].Although wet AMD has beenmanaged with anti-vascular endothelial growth factor (VEGF) treatment, no treatment is available for the dry form of the disease.

Based on compelling evidence that dysregulated complement activation and eye inflammation are a driving force for AMD pathogenesis, blockade of the AP, with consequent inhibition of the AP amplification loop, offers an interesting therapeutic optionfor treatingAMD. A pharmacokinetics study using Lampalizumab in cynomolgus monkeys has shown that therapeutic doses ( $2 \mathrm{mg} / \mathrm{animal}$ ) of the antibody injected intravitreally do not affect the AP function systemically [41]. Interestingly, the intravenous injection of high doses (20mg/animal) of the antibody increased the plasma concentrations of FD by up to 10-fold when compared to pre-injection levels, indicating that the therapeutic dose should be strictly monitored during treatment requiring intravenous administration. A multicenter phase I study to determine the safety, tolerability, and immunogenicity of the antibody has already been performed in patients with GA [42]. Given the promising results, a phase II trial followed(NCT01602120) involving 143 patients with bilateral GA. According to Genentech/Roche reports, the study has shown a $20 \%$ reduction in GA lesion progression in patients treated monthly with Lampalizumab, as compared to sham-treated individuals, and a phase III trialis currently evaluating the safety and efficacy of Lampalizumab in delaying the progression of GA. This is the first complementrelated therapy for GA to enter phase III.

Apart from Lampalizumab, Apellis is recruiting patients to test the intravitrealapplication of the C3 inhibitor APL-2- see below (NCT02461771). The C5 inhibitors eculizumab (Soliris; NCT00935883), LFG316 (NCT01255462, NCT01535950, NCT01527500) and Zimura (NCT00709527, NCT00950638) have also been tested for AMD. Eculizumab was used systemically in patients and, although well tolerated,it did not show any improvement in the disease score or drusen volume [43, 44]. Similarly, LFG316 (from Novartis)was well tolerated after intravenous application, but no efficacy was observed in terms of reduction in the need for anti-VEGF treatment (Novartis press release) and the trial was terminated (NCT01624636), 
pointing toward local AP targeting as a better therapeutic option for AMD. In contrast, based on a phase I trial,Ophthotech reported an improvement in mean visual acuity in patients receiving Zimuraintravitreally in combination with anti-VEGF. Although no further trials have been announced for AMD, the company is currently recruiting patients to test the use of Zimurafor the treatment of idiopathic polypoidal choroidal vasculopathy (NCT02397954).

\section{Targeting the Center}

\subsection{Peptidic C3 Inhibitors}

C3 is the most abundant complement protein in the serum, being present at a concentration of $\sim 1 \mathrm{mg} / \mathrm{ml}$. It is a large protein of $185 \mathrm{kDa}$ that plays a central role in complement activation and is essential for the functioning of all three pathways,as well as for the AP amplification mechanism (Fig. 2). In addition to its role in cascade activation, C3 activation fragments exert diverse biological functions via their cell-surface receptors C3aR, CR1, CR2, CR3 and CR4, complement receptor of the immunoglobulin superfamily (CRIg), DAF, and MCP. C3a is a wellstudied pro-inflammatory molecule that acts by signaling via C3aR, a G-protein-coupled receptor (GPCR). It is involved in diverse events that include immune cell activation and promotion of inflammation, mobilization of bone-marrow cells, regulation of lipid metabolism, tissue repair, and angiogenesis [2]. Furthermore, increased levels of C3a are found in several disease states, such as asthma, psoriasis, sepsis, cancer, arthritis, and cardiovascular and renal diseases [45]. Interestingly, recent studies have shown that, contrary to current belief, in some circumstances, C3a offers protection against inflammation by inhibiting C5a-induced neutrophil mobilization and preventing the infection-induced apoptosis of myeloid and lymphoid cells in the spleen [46, 47]. Another essential taskconducted by C3 fragments is the opsonization and phagocytosis of microbes and foreign bodies. The C3b fragment and its degradation products constitute a quick and efficient mechanism of body surveillance via tagging of danger-associated molecules and induction of phagocytosis via the cell receptors CR1, CR3, and CRIg in macrophages. Similarly, C3b fragments are responsible for the opsonization of immunecomplexes, which are subsequently cleared by splenic macrophages. C3b and C3dg fragments have also been shown to 
regulate the activation and differentiation of $\mathrm{T}$ and $\mathrm{B}$ cells via the receptors MCP and CR2,respectively[48, 49]. Mutations and polymorphism in the C3 gene have been associated with a risk for diseases such as AMD, aHUS, and DDD as well as the clinical outcome of certain transplantation and vaccination procedures[10].

In light of the multifaceted functions carried out by C3, long-term therapeutic blockage of this component has been regarded with caution, particularly given the susceptibility of C3deficient patients to certain pyogenic infections. Notably, though, these infections are more frequent during childhood and tend to subsideonce the patients reach adulthood, perhaps as a result of the acquisition of higher levels of IgG [50]. Furthermore, patients with C3nephritic factors who present with extremely low levels of C3 do not seem more prone to infections [51]. Undeniably, despite these hypothetical considerations, the therapeutic targeting of C3is the approach that has the broadest effect because it abrogates all three complement pathways and maytherefore benefit diverse disease states that are not completely resolved by the inhibition of a single pathway[52] (Fig.3). Furthermore, the advent of small-sized C3 inhibitors with highly favorable pharmacokinetics profiles (e.g. next-generation compstatin analogs) has made the application of systemic C3 interception possible as it can be swiftly interrupted to allow recovery of C3's activity in case of acute infections.

The compstatin family of C3 inhibitors comprises a series of cyclic peptidesthat inhibit the interaction between C3 and the convertases, thereby preventing complement activation along all three pathways [53, 54].The first C3 inhibitor from the compstatin family tested in the clinic was POT-4 (Potentia Pharmaceuticals).After a successful phase I trialof POT-4 for the treatment of AMD (NCT00473928), phase II studies did not show the expected efficacy, perhaps because of the low dose regimenadopted by the study (NCT01157065, NCT01603043). Also from the compstatin family, both APL-2 from Apellis Pharmaceuticals and the most next-generation molecule AMY-101 from Amyndas Pharmaceuticals have been granted orphan drug status for the treatment of PNH (Table 1). The molecular insights gained regardingcompstatin function have led to optimization of the original 13-amino acid peptide and the design of analogs with improved efficacy, stability, and pharmacodynamic properties[54]. Challenging the traditional view that C3 inhibition is unwise and that therapeutic peptides have short half-lives,Cp40 (and the Cp40-based therapeutic AMY-101)haveshown a favorablepharmacokinecticprofile [55] and 
promising results in preclinical studies of $\mathrm{PNH}$, periodontal disease, hemodialysis-induced inflammation, and C3 glomerulopathy[52, 54]. One of these analogues (termed Cp40), which showed sub-nanomolar binding affinity for C3, built the base for the development of AMY-101. While the first clinical trial using AMY-101 for the treatment of PNH is expected later in 2015,Apellis is currently recruiting patients to start a phase I study with APL-2 for PNH in patients with a poor response to eculizumab(NCT02264639) and phase II studies for AMD; see above (NCT02461771).

\section{Paroxysmal Nocturnal Hemoglobinuria}

PNH is a clonal hematopoietic disorder characterized by hemolytic anemia, bone marrow failure, and thrombotic events[56]. It preferentially affects young adults, with an estimated incidence of $1 / 1,000,000$. PNH occurs as a result of a somatic mutation in the phosphatidyl-inositol glycan class A (PIG-A) gene that affects the biosynthesis of the glycosyl-phosphatidyl-inositol (GPI) anchor in certain hematopoietic stem cells. As a consequence, the expression of GPI-linked cellsurface molecules is impaired [57]. Among these proteins are the complement regulators DAF and CD59. In their absence, the formation of the C3convertases (DAF) and MAC (CD59) on cell surfaces is not properly regulated, making the erythrocytes susceptible to complement-mediated intravascular lysis[58]. PNH is a life-threatening disease, with death usually occurring as a result of thrombosis, hemorrhage, or infections secondary to bone marrow failure.

Until the beginning of the 2000s, the treatment for PNH was only symptomatic and included transfusions, erythropoietin, glucocorticoids, and anticoagulants. The introduction of the anti-C5 antibody eculizumab into the clinic constituted a breakthrough in the treatment of $\mathrm{PNH}$, since the inhibition of MAC formation prevented intravascular hemolysis. Consequently,eculizumab therapy became the standard of care for PNH patients because it achieved a reduction in the number of transfusions needed (or even eliminated them entirely),as well as a reduction in the number of fatal thromboembolic events[59, 60]. Despite the unquestionable benefits of anti-C5 for PNH therapy, the clinical response toward eculizumabis not uniform. The presence of aplastic anemia and polymorphic variants of the $C 5$ and CR1genes 
that render the individual resistant to the drug[61, 62] may account for the variability. Furthermore,patients on eculizumab develop C3-mediated extravascular hemolysis as a consequence of the uncontrolled complement activation upstream of C5(because of the absence of DAF). Therefore, there is an accumulation of PNH erythrocytes opsonized with C3 fragments, and these erythrocytes are eventually phagocytosed by liver and spleen macrophages[63, 64]. Given this scenario, therapeutic intervention at the level of C3 could offer a more effective approach for PNH. Additional C5 inhibitors (see below, Table 2) are being tested as alternative therapeutics for PNH. A phase I trial (NCT02083666) with theC5-targetting affibody SOBI002 has been suspended because of adverse events, and the company Alnylam is recruiting healthy individuals and PNH patients to evaluate the safety, tolerability, and pharmacokinetics of the anti-C5 RNAi ALN-CC5 in a phase I/II study (NCT02352493).

Alongside the C5 inhibitors, the AP inhibitors TT30 and mini-FH have been shown to completely inhibit the hemolysis of PNH erythrocytes and to prevent the deposition of C3 fragments on the surviving erythrocytes in anin vitro PNH assay [65, 66]. While both of these strategies may be able to prevent both intravascular and extravascular hemolysis in $\mathrm{PNH}$ patients, further evidence in human trials is still lacking, since mini- $\mathrm{H}$ is still in the pre-clinical development phase, and a clinical trial with TT30 has been prematurely terminated because of enrollment issues (NCT01335165). In addition, as mentioned above,the Cp40-based C3 inhibitor AMY-101 and APL-2 have received orphan drug designation for the treatment of PNH.Cp40 and a PEGylated derivative thereof have been shown to effectively protect PNH erythrocytes from hemolysis and prevent the deposition of C3 fragments in vitro[67];Apellis Pharmaceuticals is currently recruiting PNH patients with a poor response to eculizumabfor a phase I trial (NCT02264639).

\subsection{Profiting from the Natural Regulators}

An alternative and elegant way to block C3 would be to take advantage of the natural C3 inhibitors found in vivo,such as CR1 and FH. Indeed, the use of complement regulators would offer a more physiologic option, especially in the treatment of chronic diseases.Since CR1 can 
inhibit all three pathways by acting as a cofactor for FI and promoting the decay of the C3 and C5convertases (Fig. 3), a recombinant form of soluble CR1 (also known as TP-10 and CDX1135)(Table 2) has been expressed in Chinese hamster ovary cells and has shownefficacy in reducing myocardial IRI in a rat model [68]. CDX-1135has been evaluated in clinical studies by Celldex, who performed a phase I trial for DDD (NCT01791686). Although this trial was terminated because of slow enrollment, an earlier phase II trial with TP10 for the treatment of cardiopulmonary bypass syndrome has been completedby Avant (NCT00082121). Althoughit has been shown to be safe, well tolerated, able to protect vascular function in children undergoing cardiopulmonary bypass and to decrease the incidence of mortality and myocardial infarction in males [69],CDX-1135 is no longer in the pipeline atCelldex. Interestingly, though, the University of Iowa is sponsoring a phase I trial for TP10 in the treatment of DDD (NCT02302755). In a case of compassionate use of TP10, an 8-year-old patient with severe DDD with a rapid progression received seven doses of the inhibitor, which was able to improve the child's levels of serum C3 and normalize the activity of the terminal pathway, therefore encouraging further studiesof its potential use for C3 glomerulopathy[70].While this compound bears promise with regard to efficiently and selectively inhibiting complement, such a largesized protein may encounter problems with production and elevated costs.

In an attempt to use the inhibitory potential of $\mathrm{FH}$, theiC3b/C3dg-binding domain of human CR2 was fused with the AP inhibitory domain of human FH to create TT30, of $65 \mathrm{kDa}$ (Alexion Pharmaceuticals)(Table 2, Fig. 3). This elegant design yielded a chimeric protein that is not only able to selectively modulate the AP but also to provide local inhibition of complement only in the cells and tissues affected by C3 deposition [71].As mentioned above,TT30 has shown promise in models of PHN [65]; however,no further plans for clinical development have been announced by Alexion. In the case of mini-FH, protein engineering was used to express a recombinant molecule containing the FH complement control protein domains (CCP) 1-4 linked to CCP19-20 via a polyglycine linker, with CCP1-4 corresponding to the regulatory domains and CCP19-20 to the C3 binding site. This resulting mini FH molecule,(43 kDa; compared to 150 $\mathrm{kDa}$ of the parent protein FH)(Table 2, Fig. 3) retained the regulatory activity of FH and proved to bevery efficient in inhibiting the in vitrodeposition of C3b on erythrocytes with a PNH- 
induced phenotype [66].Despite the promise of such targeted inhibitors,none of the FH-based therapies seems to be in active preclinical or clinical development.

\section{C3 glomerulopathy}

According with the latest consensus report by Pickering et al., C3 glomerulopathy refers to a group of rare renal disorders characterized by the presence of C3 and the absence or limited deposition of immunoglobulins in the renal tissue, where the pathology is triggered by the local imbalance in complement activation and leads to proteinuria, hematuria, and renal failure[72]. This condition has an annual incidence of 1/1,000,000. C3 glomerulopathy is subdivided intoDDD and C3 glomerulonephritis (C3GN). Whereas DDD presents with mesangial and intramembranous highly electron-dense deposits, C3GN shows isolated and less-dense deposits in the mesangial, subepithelial, subendothelial and intramenbranous areas of the glomeruli [73]. The local complement imbalance is triggered by the presence of nephritic factors: autoantibodies against the C3 convertase that stabilize and prolong the convertase's half-life, generating a hyperactive AP, autoantibodies against other components of the AP such as FB and FH, or mutations in the AP regulators FH or FI [73, 74].Half of the patients suffering from this condition progress to kidney failure within 10 years of diagnosis. Further, kidney transplantation is not recommended, because allograft loss and disease recurrence are observed in more than $50 \%$ of all cases. Current management of the disease includes drugs for blood pressure control, such as angiotensin-converting enzyme inhibitors, and immunosuppressive therapy [73].

Since C3 glomerulonephritis is a complement-mediated disease, one would expect that anti-complement therapy would improve patients' quality of life or even resolve all of the symptoms if applied soon after diagnosis. Unfortunately, the phase I clinical trial (NCT01791686) to evaluate the safety and efficacy of CDX-1135 in the treatment of patients with DDD was terminated in March 2014 as a result of declaredportfolio prioritization because of slow enrollment and the variable spectrum of potential complement abnormalities in DDD patients. 
The antibody eculizumab and the recombinant minibodyMubodina, both targeting C5, have received orphan drug designation for C3 glomerulopathy (Table 1). Although no further progress has been reported for Mubodina, eculizumab has been used in eight patients with C3 glomerulopathy[75] and also tested in six patients enrolled in an open-label study [76, 77]. The anti-C5 therapy resulted in decreased proteinuria and decreased serum levels of albumin and creatinine in seven out of the eight cases, but one patient presented with a progression of the disease. As for the six patients in the open-label study, four showed varied degrees of improvement, but two patients experienced declining renal function [76, 77]. These results indicate that while eculizumab may be beneficial in some cases, other blockade approaches need to be considered.

In line with thenotion of alternative approaches, TP10 is currently being tested for DDD (NCT02302755).Also, preclinical evidence hassuggested the value of using the C3 inhibitor AMY-101 of the compstatinfamily to treat C3 glomerulopathy[78]. Because the pathology is indicative of a dysfunctional AP, C3 blockade could constitute a useful treatment strategy for preventing the formation of C3 convertases and the amplification loop. Indeed, the compstatinanalog Cp40 prevents complement-mediated lysis of sheep erythrocytes in sera from patients,complement dysregulation in the presence of patient-derived autoantibodies to the C3 and C5convertases, and complement dysregulation associated with disease-causing genetic mutations in invitro studies [78].

\section{Targeting the Effectors}

\subsection{C5 Inhibitors}

Like complement C3, C5 also plays a pivotal role in complement activation, since all three pathways culminate in the cleavage of C5. C5 is $185 \mathrm{kDa}$,has a structure similar to that of C3, and is present at $\sim 75 \mu \mathrm{g} / \mathrm{ml}$ in the plasma. Once C5 is cleaved and the fragments C5a and C5b are formed, the C5b fragments attach to the cell membrane, where they participate in the further assembly of the MAC (Fig. 2). Conversely, C5a is released and is able to bind to the C5aR1 receptors that are highly expressed on myeloid cells or to the C5aR2 (also known as C5L2) 
receptors, which are mainly expressed on neutrophils. Whereas the physiological role of C5aR2 is still debatable, C5aR1 is one of the most-studied molecules in the complement field,reflecting the fact that C5a-induced C5aR1 signaling is a potent trigger of cell activation and inflammation: Itstimulates the induction of cytokines, the polarization of T-cell responses, and the exacerbation of many pathological conditions such as cancer, neurologic diseases, sepsis, arthritis, periodontitis, and liver disease,among others[45, 79]. C5 deficiency has been described in approximately 50 individuals worldwide and is associated with recurrent infections caused by Gram-negative bacteria, particularlythose of the genus Neisseria. Whereasthe MAC,and consequently C5,is important for the immune response againstNeisseriabecausephagocytosis and intracellular killing do not appear to be sufficient to eradicateNeisseria,the impact of the MAC on the control of other bacterial infections is currentlyunder debate[50].

In view of the critical role of C5 in inflammation and MAC formation, targeting of C5 is currently the most-explored complement-related therapeutic strategy (Fig. 3). As of this date,sixdifferent molecules that intercept complement at the level of C5/C5a are undergoing clinical trials for the treatment of various diseases, and other inhibitors are close to the clinical phase. Whereas such interest likely reflects the assumption that intervention downstream of C3 would have less impact on host defense function, it may limit the applicability in certain diseases (see above).

Eculizumab (Soliris) by Alexion Pharmaceuticals (Table 1), a monoclonal antibody directed against C5, simultaneously blocks the generation of C5a and MAC assembly. It is the first product licensed specifically to inhibit the complement system and has been the prevailing treatment for PHN and aHUS since 2007 and 2011, respectively. Clinical trials have established the safety and efficacy of this inhibitor for PNH and aHUS[60, 80]; however, as a cautionary measure, individuals under eculizumabtreatment are vaccinated against meningitis prior to the treatment.Apart from PNH and aHUS,eculizumabhas received orphan drug status for dermatomyositis, idiopathic membranous glomerular nephropathy, NMO, myasthenia gravis (MG), and the prevention of graft rejection following solid organ transplantation (Table 1). To date, this C5 inhibitor has been tested in 28 clinical trials and is currentlyunder evaluation in an additional 25 trials for numerouspathologies. While this drug has undoubtedly revolutionized the treatment of PNH and brought the attention of pharmaceutical companies to complement 
therapeutics, it has a major drawback:Its elevated cost of US\$500,000 per patient per yearhasled to Forbes magazine awardingeculizumab the title of “most expensive drug in the world”[81].

Eculizumab’ssuccess has clearly awakened pharmaceutical companies to complement therapeutics. As such, a number of startup and even some large companies have been investing in the development of anti-C5 molecules. A second C5 antibody, LFG316, developed by Novartis, is in phase II trials for AMD (NCT01527500). Regardless of its initial disappointing results (see above), a new trial is currently evaluating the impact of different dosages of the drug. This compound has also entered phase II trialsfor panuveitis (NCT01526889). Adienne Pharma and Biotech is developing recombinant minibodies against C5, in which the heavy and light chain variable fragments are fused and linked as a single chain with the IgG hinge region. The resulting compound, Mubodina,has been designated anorphan drug for the treatment of membranoproliferative glomerulonephritis and aHUS (Table 1). In addition, a Mubodina derivative called Ergidina, which bears an arginine-glycine-aspartic acid (RGD) tail to target endothelial cells, has received orphan drug status for the prevention of posttransplantationIRI (Table 1).

Efforts to circumvent the high production cost of antibodieshas impelled the development of other classes of molecules with therapeutic capability,such as aptamers, small proteins, affibodies, and RNAi. Zimura (ARC1905), a PEGylated aptamer developed by Ophthotech,has completed phase I trials for AMD (NCT00709527, NCT00950638) and shown positive safety results. Currently, the company is recruiting patients for a phase IItrial for the treatment of idiopathic polypoidalchroroidalvasculopathy (NCT02397954). Also, the 16-kDa small protein Conversin (also termed OmCI, fromVolution Immuno-Pharmaceuticals)(Table 2), originally isolated from the tick Ornithodorosmoubata,is able to prevent MAC- and leukotriene B4-derived effectsand has shown promising results in preclinical disease models [82]. One caveat, though, is potential immunogenicitybecause the molecule is derived from a pathogen; thisconcern should be carefully considered when advancing to clinical protocols. Also, the small molecule SOBI002 (12 kDa) based on the Affibody platform, by Swedish Orphan Biovitrum, is fused to an albumin-binding protein aimed at increasing the half-life of the molecule(2 weeks) [83]. Unfortunately, the phase I trial to test the safety, tolerability, and pharmacokinetics of the compound in healthy volunteers bas been recently suspended because of adverse events 
(NCT02083666), and no further development has been announced. Finally, the RNAi ALN-CC5, by Alnylam Pharmaceuticals, is being tested in healthy volunteers and PNH patients in a phaseI/II trial (NCT02352493), and preliminary results from 12 healthy volunteers have shownacceptable safety and efficacy [84]. It is still unclear, though, whether this therapy reaches the level of effectiveness achieved by eculizumab.

C5 inhibitors are also being tested for the treatment of severalother orphan diseases,as discussed below.

\section{Dermatomyositis}

Dermatomyositis is an idiopathic inflammatory myopathy characterized by skeletal muscle inflammation that causesskin lesions and muscle weakness. It presentsat an annual incidence of 9/1,000,000 [85] and is associated with high morbidity, given that the development of muscle weakness adversely affects physical capacities over time, with potential involvement of the pulmonary, gastrointestinal, and cardiac systems. Furthermore, patients diagnosed at an older age or with rapid onset of the disease, the presence of skin necrosis, or a low baseline level of complement C4 have an increased risk of developing malignancy [86].

The exact pathogenesis of dermatomyositishas not yet been elucidated; however, patients usually present with autoantibodies directed in particular against synthetases and nuclear factors; environmental triggers such as infections may also play a role in the disease. Complement is implicated in the disease, sincehyperactivation and MAC formation lead to lysis of endothelial cells and damage to the capillaries. As a result, the number of capillaries is reduced throughout the muscle, which therefore suffers from ischemia. Complement dysregulation also causes a local inflammatory environment by triggering the release of pro-inflammatory cytokines and the recruitment of inflammatory cells [87].The therapeuticgoal is to improve muscle strength and enable the individual to perform daily activities. As with the majority of autoimmune diseases, current treatment aims at controlling the exacerbated inflammation with corticosteroids and/or immunosuppressants[88]. The use of high-dose intravenous immunoglobulin (IVIg) has also proved effective [89]. 
In 2000,eculizumabwas granted orphan drug status from the FDA to treat dermatomyositis(Table 1). A pilot study (NCT00005571) was then conducted to evaluate the safety and efficacy of the drug on 13 patients with the disease undergoing concomitant treatment with moderate doses of methotrexate or steroids. Though the trial results were positive regarding safety andtolerability, no further information was released by the company. Nevertheless, eculizumabhas been used to treat a 16-year-old girl with severe symptoms of dermatomyositis and TMA who failed to respond to a variety of corticosteroids, immunosuppressants, and IVIG [90]. Treatment witheculizumab was effective in improving her clinical condition and biological parameters, indicating the importance of further studies of complement-related therapy for dermatomyositis.

\section{NeuromyelitisOptica}

$\mathrm{NMO}$ is an inflammatory disease of the central nervous system characterized by demyelination of the spinal cord and optical nerve; it has an incidence of 0.05-0.4/100,000. Patients present with severe, acute attacks of paralysis, blindness, and sensory impairment. The mean age of onset ranges from 32.6 and 45.7 years, and the disease is more frequent in females than males [91]. The disease is characterized by the presence of autoantibodies against the astrocyte water channel protein aquaporin-4 [92]. These autoantibodies activate the $\mathrm{CP}$ on the astrocytes, which are devoid of complement regulators such as DAF, MCP, and CD59 [93]; therefore, they cause a local inflammatory response with infiltration of granulocytes and macrophages, leading to oligodendrocyte damage, demyelination, and neuronal death [94]. It is noteworthy that in animal models, IgG from NMO patients is unable to cause inflammation, demyelination, or neuronal death in the absence of complement [95]. Furthermore, the concentrations of the activation product C3a are directly correlated with the severity of the neurological disability and the levels of anti-aquaporin antibodies [96, 97].

Current NMO therapy is focused on the control of acute disease, improvement of neurological disability, and prevention of future attacks. The standard procedure follows the use of corticosteroids and plasma exchange for acute and chronic cases, with the addition of immunosuppressants if required [98]. Eculizumab has recently been tested in a pilot study in 14 
female NMO patients (average age: 41.1 years) who were positive for aquaporin antibodies. Overall, the anti-C5 therapy was well tolerated, reduced the attack frequency, and stabilized or reduced the neurological disabilities in the patients. During the treatment, 12 of the 14 patients had no attacks, and no patient presented with any worsened disability [99], indicating that complement has a pivotal role in the pathogenesis of NMO. Notably, the patients were off the usual therapy with corticosteroids and immunosuppressants during the trial. A phase III trial is currently being conducted to evaluate the safety and efficacy of the drug in patients with relapsing disease (NCT01892345).

The safety of C1INH has also been evaluated in 10 NMO patients. Here, C1-INH was added to the current standard therapy, i.e. high doses of corticosteroids. The combined therapy was safe, and although the trial was not designed to measure efficacy, the scores for disease severity decreased from a median of 4.5 on admission to 4.0 on discharge, and then down to 2.5 at the 30-day follow-up, when they did not differ from the median baseline score [14]. Whereas no comparison can yet be drawn regarding the efficacy of anti-C5 versus anti-C1 inhibition strategies, these trials clearly indicate the potential for targeting complement in NMO disease.

\section{Myasthenis gravis}

MG is a heterogeneous autoimmune disorder characterized by a defective postsynaptic neuromuscular transmission that results in fatigable weakness of the voluntary muscles. It has an incidence of 1/250,000 and affects mainly females before the age of 40 and both males and females after the age of 50. It is caused by the presence of autoantibodies against components of the neuromuscular junction, specifically, the anti-acetylcholine receptor (AChR), anti-musclespecific receptor tyrosine kinase (MuSK) and/or anti-lowdensity lipoprotein receptor-related protein 4 (LRP4). The muscles that control the eyes and eyelid movementare particularly susceptible to weakness, but othermuscles for chewing, talking, and swallowing arefrequently involved. In addition, the respiratory muscles can be affected, leading to acute respiratory failure [100].

Approximately 90\% of the patients with generalized MG have antibodies against the AChRs, which are essential for muscle contraction. These antibodies are mainly of the IgG1 and IgG3 isotypes and trigger the pathology by direct blockade of the ACh binding site, cross-linking of the AChRs,and endocytosis and degradation of the receptors and activation of the complement 
system [101]. In contrast, the MuSK antibodies are of the IgG4 isotype and are thus unable to activate complement. Unfortunately, anti-MuSK MG is associated with an increased risk of myasthenic crises, and these patients do not respond well to acetylcholinesterase inhibitors and thymectomy(although Rituximab appears to be more effective in these patients than in patients with AChR MG)[102]. The third type of antibody, the anti-LRP-4 MG, accounts for $1 \%$ of all generalized MG [103] and, like the AChR type, the antibodies are of the IgG1 isotype, and complement is involved in the damage to the postsynaptic membranes[101].

Approximately $10 \%$ of all MG patients have a thymoma, and $60 \%$ present with thymic hyperplasia, which may play a role in the initiation of the disease through the expression of selfantigens and the impaired negative selection of auto-reactive T cells [101]. Whereas it is well appreciated that thymic cells produce AChR antibodies [104], thymectomy does not eliminate the antibody production, indicating the presence of other sources of autoantibodies in MG. These patients usually respond well to acetylcholinesterase inhibitors and immunosuppressive drugs, and thymectomy may be recommended in some cases [105].

The involvement of complement in MG pathophysiology is well appreciated.Apart from the presence of the MAC at the neuromuscular junction during the disease, the blockade of complement components such as C1q, C3, C5, and C6 has been shown to protect against experimental MG [106]. Furthermore, the absence of the complement regulators DAF and CD59 is directly correlated with a more severe course of the disease during experimental MG [107].Whereas complement targeting is not expected to work as therapy for patients positive for MuSK autoantibodies, complement intervention may be beneficial for the other cases. A phase II trial has been conducted to test the safety and efficacy of eculizumab in patients with severe, generalized, and refractory MG who are positive for AChR autoantibodies. Fourteen patients were enrolled and received treatment for two periods of 16 weeks in a cross-over fashion with eculizumab or placebo. The results were promising,showingsignificant improvementin the clinical manifestations [108] and, as a result, a phase III trial is currently recruiting patients (NCT01997229).

\section{Guillain-Barré Syndrome (GBS)}

The term GBS refers to a variety of post-infectious neuropathiesthat are clinically heterogeneous and predominantly seen in males, with an incidence of 1/100,000. GBS typically occurs after a 
bout of infectious disease in which antibodies that crossreact with gangliosides at nerve membranes are generated, causing nerve damage or impairment of nerve conduction. The type and location of the infection determine the type and clinical course of GBS. Serological studies have shown that Campylobacter jejuni is the most frequent antecedent infection, but other associated infections include cytomegalovirus, Epstein-Barr virus, hepatitis E virus, Mycoplasma pneumonia, and Haemophilus influenza[109]. The most characteristic clinical feature is limb weakness. Lumbar and muscle pain, autonomic dysfunction, and respiratory problems are also observed. Currently, IVIg and plasma exchange are the mainstays of treatment, and the prognosis is variable, depending on the form of GBS, and the outcomes can range from complete recovery to death[109, 110].

It has been shown that $C$. jejuni, Haemophilus, and cytomegalovirus have gangliosidelike structures that may be responsible for the production of antibodies that crossreact with gangliosides on the nerve cells. Such antibodies are of the IgG1 and IgG3 subclasses, which activate complement leading to MAC formation and take part in the myelin destruction and local inflammatory response that includes infiltration of macrophages. Whereas the proinflammatory effects of C3a and C5a are not excluded in this disease, animal studies have shown that the major acute injury only occurs in the presence of the MAC, and aninjury model has been formulated in which an uncontrolled influx of calcium through the MAC results in mitochrondrial and cytoskeletal dysfunction [111].

Because studies have shown that eculizumab preventsthe electrophysiological sequelae and lesions when anti-ganglioside antibodies are incubated with neuromuscular junctions in vitro,with normal human serum as a source of complement [111], a phase II trial has been planned andis currently recruiting patients to evaluate the safety and efficacy of eculizumab in the treatment of GBS (NCT02029378).

\section{Multifocal Motor Neuropathy (MMN)}

MMN is a motor neuropathy characterized by progressivedistal asymmetric limb weakness thatusually starts and predominates in the upperlimbs, with minimal or no sensory 
impairment,and follows a chronic evolution. The onset usually occurs before the age of 50, and males are predominantly affected,with a prevalence of $0.6 / 100,000$. The morbidity linked to the disease is variable and can lead to a moderate-to-major impairment of daily activities, including walking ability. Although the pathophysiological mechanisms are not fully understood, the disease is often associated with serum IgM antibodies against the ganglioside GM1. MNN does not respond well to corticosteroids and, plasmapheresis and IVIg, though the first-line therapy offer only transient results, often requiring repeated infusions [112, 113].

An animal model of MMN is not available, but serum from patients with anti-GM1 IgM antibodies is known to trigger complement activationin vitro.The extent of the complement deposition is correlated with the antibody titer and is reduced after IVIg treatment in a dosedependent manner[114]. It is likely that complement is involved in the pathological mechanisms of MMN as it is in GBS disease. An open-label trial in $13 \mathrm{MMN}$ patientshas been conducted to evaluate whether co-administration of eculizumab with high-dose IVIgis safe and efficient. Whereas complement targeting abrogated MAC formation in the plasma regardless of the concomitant use of IVIg, and it resulted in increased muscle strength, it did not affect the requirement for IVIg, indicating that anti-C5 therapy alone is not sufficient to prevent the disease, at least with such a short treatment period Fitzpatrick[115]. No further studies have been announced in this area.

\section{Transplantation}

Complement has long been implicated in the outcome of solid organ transplantation, and the activation product C4d is currently being used as a biomarker of chronic antibody-mediated rejection (AMR)[116]. Both the tissue injury induced by IRI and the rejection episodes are strongly correlated with excessive complement activation and the associated consequent trigger of diverse inflammatory pathways. Both systemic complement and components locally produced by the transplant organ and infiltrating immune cells appear to play critical roles. Indeed, C3 synthesis in the transplanted kidney was shown to be increased and dependent on the duration of cold ischemia[117]. C3 production by the donor kidney tipically reaches a peak after reperfusion, indicating the potential for complement inhibition during organ collection as means of decreasing tissue damage and improving the transplant outcome. IRI is particularly critical in the organs collected after circulatory arrest of the donor, since local production of complement 
proteins and increased levels of pro-inflammatory markers have been observed in the kidneys of deceased donors[118]. Several inflammatory pathways participate in the genesis of IRI, and complement is a key modulator of most, if not all, of these processes[119]. The resulting cellular injury is mainly attributed to the terminal pathway products C5a and C5b-9, with consequent release of pro-inflammatory factors, neutrophil degranulation, and endothelial cell activation and death[120, 121]. While current evidence strongly favors a role for the AP and LP in triggering complement-mediated IRI, the role of the CP is still controversial, and key information, including which complement components are involved in the injury and where they are produced and activated, still remains unknown[121].

In transplantation settings, complement activation is observed not only in response to IR but also during episodes of cellular and antibody-mediated rejection. Increased levels of complement activation products have been detected in the plasma, urine, and transplanted organ in patients showing rejection of cardiac or renal transplants. During episodes of cell-mediated rejection, the transplanted kidney contributes with $10 \%$ (5\% in physiologic conditions) of the circulating pool of C3 [122].Imbalanced complement activation leads to direct deposition of MAC and indirect damage to the renal parenchyma, by enhancing $T$ cell responses against the donor organ[117, 123]. Furthermore, in episodes of AMR, pre-formed or induced antibodies present in the host recognize antigens in the graft and activate complement and inflammation, ultimately leading to graft rejection[124]. Notably, C3 fragments have been shown to modulate B-cell activation and antibody production upon signaling via CR2 in B cells[125]. Episodes of antibody-mediated rejection, as observed in ABO-incompatible and HLA-sensitized transplant patients, are particularly of concern, since they result in catastrophic hyperacute AMR and an extremely high rate of graft loss[124].

In line with these findings, complement inhibition during transplantation has been shown to be effective in diminishing IRI and increasing graft survival in several animal models, and the efficacy of complement-targeted therapeutics in clinical settings of transplantation is currently being evaluated[116]. The use of Eculizumab also has showed promising results, for preventing AMR in patients with HLA-specific antibodies and reversed established rejection[126, 127]. Furthermore, in a presensitized non-human primate (NHP) model of kidney transplantation, complement depletion with cobra venom factor (CVF) resulted in organ accommodation; i.e., 
endothelial cell resistance to antibody-mediated destruction, and long-term engraftment[128]. Despite these promising results, further work is still needed to better understand the mechanisms by which complement influences the balance between graft tolerance and rejection and to characterize the most efficient targeting approach for improving kidney transplant outcomes. Eculizumab, ergidina and ruconest have been granted with orphan drug status for the prevention of injury, delayed graft functionor rejection after transplantation (Table 1). Ten distinct clinical trials are underway to test eculizumab for AMR and delayed graft function mainly in kidney transplantation. In addition, the C1-INHBerinert has been shown to be safe and well tolerated when used after kidney transplantation in HLA sensitized patients [12] and a second trial is currently recruiting patients to evaluate the efficacy of Berinert in preventing delayed graft function and IRI (NCT02134314).

\subsection{C5a and C5aR Inhibitors}

As an alternative to the prevention of C5 cleavage,a distinct strategy to interfere with the effector functions of complement is the abrogation of C5a-mediated effects. This approach mayoffer clinical benefits for diverse conditions in which inflammation is a major driving force for the disease.It is particularly interesting because the targeting of C5a can hamper inflammation without affecting either opsonization or MAC-mediated functions (Fig. 3). Blocking the C5aC5aR interaction with small molecules has long been pursued as a therapeutic strategy [129, 130]. However, thus far none of these molecules hasproduced the expected clinical results, and most have not survived the process of clinical development. The small molecule CCX168 (from ChemoCentryx)(Table 1) is the only C5aR antagonist that is currently being tested in clinical trials. It holds an orphan drug designation for anti-neutrophil cytoplasmic antibody (ANCA)vasculitis and aHUS and is in phase II trials for ANCAvasculitis (NCT01363388, NCT02222155) as well as IgA nephropathy (NCT02384317) and aHUS (NCT02464891).CaCP29 (IFX-1, from InflaRx)(Table 2) is a monoclonal antibody against C5a that has completed a phase I trial (NCT01319903) for safety evaluation and is currently in phase IItestingfor the treatment of sepsis (NCT02246595). Of note, C5a has an extremely rapid turnover, which may undermine the therapeutic capacity of the C5a inhibitors. 


\section{ANCA-associated Vasculitis}

ANCA-associated vasculitis comprises a group of clinical heterogeneous disorders characterized by inflammation of the small blood vessels and anti-neutrophil antibodies directed against either proteinase 3 or myeloperoxidase [131]. Although the clinical features are heterogeneous and reflect the location of the vessels affected, some common symptoms include fever, anemia, weight loss, rash, synovitis, and involvement of the respiratory tract and kidneys [132]. As is true for other heterogeneous and immune-related diseases, treatment is based on corticosteroids and/or immunosuppressantsand plasma exchange in more severe cases [131].

Both autoantigens, proteinase 3 and myeloperoxidase, are typically retained within neutrophilic granules. When an inflammatory stimulus such as a pro-inflammatory cytokine, complement activation,or ANCA-IgG production occurs, the extracellular expression of the two antigens is increased, leading to the recruitment of inflammatory cells and further activation of neutrophils,with subsequent organ damage and dysfunction [133, 134]. Because IgGs are absent or only scarcely found in the affected tissues [132], ANCA-induced neutrophil activation is considered the main factor in the disease pathogenesis. In line with this concept, C4-deficient mice are not protected against the disease, whereas FB or C5 deficiency confers protection [135]. Furthermore, FB and properdin have been detected in the glomeruli of patients, indicating a role for the AP in renal damage; also, systemic activation of AP has been demonstrated in the plasma of patients with active disease [136, 137]. In addition, C5aR is essential for the development of the disease [134], since C5a has been defined as a key factor in the priming of neutrophils, with consequent expression of the autoantigens proteinase 3 and myeloperoxidase [138-140].

Based on our understanding of the pathophysiological mechanisms of the disease,therapeutic intervention targeting either the AP or the C5a-C5aR interaction seems a logical approach. Indeed, a phase II trial is recruiting patients to test the safety and efficacy of the C5aR antagonist CCX168 in the treatment of ANCA-associated renal vasculitis (NCT0136388). A second trial with eculizumab was withdrawn because of difficulties in enrolling patients (NCT01275287). 


\section{Conclusions}

The perception of the complement system as a critical factor that tips the balance between homeostasis and pathological states has brought new enthusiasm to the field of complement. Aided by animal models and genomic and structural studies, the unfolding of complementrelated mechanisms that drive health and disease has advanced considerably in the past decade. The acquired knowledge has prompted the design of distinct and, in some cases, very creative strategies to interfere therapeutically at various stages of the cascade. Some of these approaches, such as the use of C1-INH, anti-C1s and anti-MASP antibodies, are very specific, aiming at the disruption of a single pathway. While it is likely that the immune response will be less compromised by this approach, it remains to be determined whether such specific targeting will be sufficient to induce relevant clinical benefit, and in which disease states. More comprehensive strategies that envisage the blockade at the level of C3 may fulfill the requirement for more robust inhibition in cases in which more than one pathway is involved in the pathology. In addition, strategies based on complement regulators that are directed to sites of complement activation may offer a type of intervention closely resembling the physiological control of complement. In addition, the abrogation of C5-mediated effects is a good option for diseases in which the MAC and/or C5a is the driving force.

The clinical experience acquired with the drugs eculizumab and C1-INH has undeniably shown that complement-targeted therapeutics can be safe, effective, and profitable. Notably, the stock price of Alexion has increased by more than $600 \%$ in the past 5 years. The high costs for eculizumab and C1-INH, and the therapeutic focus on the orphan disease market, raise a red flag as to whether the interest of the pharmaceutical companies in complement-target therapy is predominantly financial. Whereas the clinical trials currently evaluating eculizumab for the rare diseases mentioned above are of extreme importance because they may offer more effective therapies and lead to improved quality of life for the patients, the licensing of eculizumab for numerous diseases may also put enormous pressure on the public health system. As discussed in this review, small molecules and peptidic compounds could offer more cost-effective treatment options.Hence, it is important that more effort is placed on the development of additional complement-related therapies with lower cost and even higher effectiveness. 
At this date, over 40 clinical trials are ongoing to evaluate different classes of complement inhibitors in numerous diseases. The next few years will hopefully bring valuable information concerning the safety and efficacy of distinct strategies for complement targeting. For orphan diseases in particular, this may represent a great improvement in the management of clinical signs and quality of life.Traditionally, rare pathological conditions and diseases with an immune component have often been tackled with corticosteroids and immunosuppressantsthat are known to induce an array of side effects. Whereas complement may not be the main trigger in several of these disorders, it may still play a pivotal role in the maintenance of an inflammatory environment that fuels the pathology. Certainly, further research will be required to select the proper strategy for complement inhibition and to validate the involvement of complement in specific diseases, since virtually any disease with an inflammatory component may benefit from the disruption of complement activation. 


\section{Acknowledgements}

We thank Deborah McClellan for her excellent editorial assistance. This work was supported by National Institutes of Health grants AI068730, AI030040, and AI097805, the National Science Foundation grant 1423304, and by funding from the European Community's Seventh Framework Programme under grant agreement number 602699 (DIREKT).

\section{Declaration of Interest}

JD Lambris and D Ricklin are inventors of patent applications that describe the use of complement inhibitors for therapeutic purposes. JD Lambris is the founder of Amyndas Pharmaceuticals, which is developing complement inhibitors. AM Risitano received research funding from Alexion Pharmaceuticals, Amyndas Pharmaceuticals, Alnylam Pharmaceuticals, Rapharma and Novartis and is a consultant for Alnylam and RA Pharma. The other authors declare no financial interest or conflict. 


\section{References}

[1] I.K. Zarkadis, D. Mastellos, J.D. Lambris, Phylogenetic aspects of the complement system, Dev. Comp Immunol, 25 (2001) 745-762.

[2] D. Ricklin, G. Hajishengallis, K. Yang, J.D. Lambris, Complement: a key system for immune surveillance and homeostasis, Nat. Immunol, 11 (2010) 785-797.

[3] C. Kemper, J. Kohl, Novel roles for complement receptors in T cell regulation and beyond, Mol. Immunol, 56 (2013) 181-190.

[4] M. Kolev, F.G. Le, C. Kemper, Complement--tapping into new sites and effector systems, Nat. Rev. Immunol, 14 (2014) 811-820.

[5] D. Spitzer, L.M. Mitchell, J.P. Atkinson, D.E. Hourcade, Properdin can initiate complement activation by binding specific target surfaces and providing a platform for de novo convertase assembly, J. Immunol, 179 (2007) 2600-2608.

[6] N.S. Merle, S.E. Church, V. Fremeaux-Bacchi, L.T. Roumenina, Complement System Part I Molecular Mechanisms of Activation and Regulation, Front Immunol, 6 (2015) 262.

[7] B.P. Morgan, The membrane attack complex as an inflammatory trigger, Immunobiology, (2015).

[8] D.D. Kim, W.C. Song, Membrane complement regulatory proteins, Clin Immunol, 118 (2006) 127-136.

[9] D. Ricklin, J.D. Lambris, Complement in immune and inflammatory disorders:

pathophysiological mechanisms, J. Immunol, 190 (2013) 3831-3838.

[10] K. Liszewski, J.P. Atkinson, Complement regulators in human disease: lessons from modern genetics, J. Intern. Med, 277 (2015) 294-305.

[11] A. Feussner, U. Kalina, P. Hofmann, T. Machnig, G. Henkel, Biochemical comparison of four commercially available C1 esterase inhibitor concentrates for treatment of hereditary angioedema, Transfusion, 54 (2014) 2566-2573.

[12] A.A. Vo, A. Zeevi, J. Choi, K. Cisneros, M. Toyoda, J. Kahwaji, A. Peng, R. Villicana, D. Puliyanda, N. Reinsmoen, M. Haas, S.C. Jordan, A phase I/II placebo-controlled trial of C1inhibitor for prevention of antibody-mediated rejection in HLA sensitized patients, Transplantation, 99 (2015) 299-308.

[13] J.J. Hofstra, I. Kleine Budde, E. van Twuyver, G. Choi, M. Levi, F.W. Leebeek, J.G. de Monchy, P.F. Ypma, R.J. Keizer, A.D. Huitema, P.F. Strengers, Treatment of hereditary angioedema with nanofiltered C1-esterase inhibitor concentrate (Cetor(R)): multi-center phase II and III studies to assess pharmacokinetics, clinical efficacy and safety, Clin Immunol, 142 (2012) 280-290.

[14] M. Levy, M.A. Mealy, Purified human C1-esterase inhibitor is safe in acute relapses of neuromyelitis optica, Neurol. Neuroimmunol. Neuroinflamm, 1 (2014) e5.

[15] C.E. Hack, A. Relan, E.S. van Amersfoort, M. Cicardi, Target levels of functional C1inhibitor in hereditary angioedema, Allergy, 67 (2012) 123-130.

[16] M.B. van Doorn, J. Burggraaf, D.T. van, A. Eerenberg, M. Levi, C.E. Hack, R.C. Schoemaker, A.F. Cohen, J. Nuijens, A phase I study of recombinant human C1 inhibitor in asymptomatic patients with hereditary angioedema, J. Allergy Clin. Immunol, 116 (2005) 876883.

[17] Z. Kelemen, D. Moldovan, E. Mihaly, B. Visy, G. Szeplaki, D. Csuka, G. Fust, H. Farkas, L. Varga, Baseline level of functional C1-inhibitor correlates with disease severity scores in hereditary angioedema, Clin Immunol, 134 (2010) 354-358. 
[18] S. Caccia, C. Suffritti, M. Cicardi, Pathophysiology of Hereditary Angioedema, Pediatr. Allergy Immunol. Pulmonol, 27 (2014) 159-163.

[19] J.A. Bernstein, HAE update: epidemiology and burden of disease, Allergy Asthma Proc, 34 (2013) 3-6.

[20] L. Truedsson, Classical pathway deficiencies - A short analytical review, Mol. Immunol, (2015).

[21] T. Keck, Site-specific therapeutic effects of protease inhibitors: effect of route of administration in experimental pancreatitis, Pancreatology, 1 (2001) 656-661.

[22] S. Berentsen, T. Sundic, Red blood cell destruction in autoimmune hemolytic anemia: role of complement and potential new targets for therapy, Biomed. Res. Int, 2015 (2015) 363278.

[23] P.L. Swiecicki, L.T. Hegerova, M.A. Gertz, Cold agglutinin disease, Blood, 122 (2013) 1114-1121.

[24] J. Shi, E.L. Rose, A. Singh, S. Hussain, N.E. Stagliano, G.C. Parry, S. Panicker, TNT003, an inhibitor of the serine protease C1s, prevents complement activation induced by cold agglutinins, Blood, 123 (2014) 4015-4022.

[25] M. Matsushita, Y. Endo, T. Fujita, Structural and functional overview of the lectin complement pathway: its molecular basis and physiological implication, Arch. Immunol. Ther. Exp. (Warsz. ), 61 (2013) 273-283.

[26] T. Olszowski, I. Poziomkowska-Gesicka, J.C. Jensenius, G. Adler, Lectin pathway of complement activation in a Polish woman with MASP-2 deficiency, Immunobiology, 219 (2014) 261-262.

[27] K. Stengaard-Pedersen, S. Thiel, M. Gadjeva, M. Moller-Kristensen, R. Sorensen, L.T. Jensen, A.G. Sjoholm, L. Fugger, J.C. Jensenius, Inherited deficiency of mannan-binding lectinassociated serine protease 2, N. Engl. J. Med, 349 (2003) 554-560.

[28] M. Noris, F. Mescia, G. Remuzzi, STEC-HUS, atypical HUS and TTP are all diseases of complement activation, Nat. Rev. Nephrol, 8 (2012) 622-633.

[29] L. Johannes, W. Romer, Shiga toxins--from cell biology to biomedical applications, Nat. Rev. Microbiol, 8 (2010) 105-116.

[30] G. Ren, B.K. Hack, A.W. Minto, P.N. Cunningham, J.J. Alexander, M. Haas, R.J. Quigg, A complement-dependent model of thrombotic thrombocytopenic purpura induced by antibodies reactive with endothelial cells, Clin Immunol, 103 (2002) 43-53.

[31] M. Riedl, F. Fakhouri, Q.M. Le, D.G. Noone, T.C. Jungraithmayr, V. Fremeaux-Bacchi, C. Licht, Spectrum of complement-mediated thrombotic microangiopathies: pathogenetic insights identifying novel treatment approaches, Semin. Thromb. Hemost, 40 (2014) 444-464.

[32] S. Heitzeneder, M. Seidel, E. Forster-Waldl, A. Heitger, Mannan-binding lectin deficiency Good news, bad news, doesn't matter?, Clin Immunol, 143 (2012) 22-38.

[33] C. Licht, L.A. Greenbaum, P. Muus, S. Babu, C.L. Bedrosian, D.J. Cohen, Y. Delmas, K. Douglas, R.R. Furman, O.A. Gaber, T. Goodship, M. Herthelius, M. Hourmant, C.M. Legendre, G. Remuzzi, N. Sheerin, A. Trivelli, C. Loirat, Efficacy and safety of eculizumab in atypical hemolytic uremic syndrome from 2-year extensions of phase 2 studies, Kidney Int, 87 (2015) 1061-1073.

[34] J.E. Volanakis, S.V. Narayana, Complement factor D, a novel serine protease, Protein Sci, 5 (1996) 553-564.

[35] D.H. Biesma, A.J. Hannema, H. van Velzen-Blad, L. Mulder, Z.R. van, I. Kluijt, D. Roos, A family with complement factor D deficiency, J. Clin. Invest, 108 (2001) 233-240. 
[36] T. Sprong, D. Roos, C. Weemaes, C. Neeleman, C.L. Geesing, T.E. Mollnes, D.M. van, Deficient alternative complement pathway activation due to factor $\mathrm{D}$ deficiency by 2 novel mutations in the complement factor $\mathrm{D}$ gene in a family with meningococcal infections, Blood, 107 (2006) 4865-4870.

[37] C.M. Stanton, J.R. Yates, A.I. den Hollander, J.M. Seddon, A. Swaroop, D. Stambolian, S. Fauser, C. Hoyng, Y. Yu, K. Atsuhiro, K. Branham, M. Othman, W. Chen, E. Kortvely, K. Chalmers, C. Hayward, A.T. Moore, B. Dhillon, M. Ueffing, A.F. Wright, Complement factor D in age-related macular degeneration, Invest Ophthalmol. Vis. Sci, 52 (2011) 8828-8834. [38] K.J. Katschke, Jr., P. Wu, R. Ganesan, R.F. Kelley, M.A. Mathieu, P.E. Hass, J. Murray, D. Kirchhofer, C. Wiesmann, C.M. van Lookeren, Inhibiting alternative pathway complement activation by targeting the factor D exosite, J. Biol. Chem, 287 (2012) 12886-12892. [39] B.P. Morgan, j. Thanassi, s. Podos, g. Yang, a. Phadke, v. Gadhachanda, g. Pais, a. Hashimoto, q. Wang, d. Chen, x. Wang, a. Agarwal, m. Deshpande, y. Huang, j. Wiles, m. Huang, Novel Small Molecule Inhibitors Targeting Complement Factor D for Therapy of Paroxysmal Nocturnal Hemoglobinuria, Abstract presented at the 56thAnnual Meeting of the American Society of Hematology, San Francisco, California, USA, December 6-9, 2014, 2014. [40] N.S. Bora, B. Matta, V.V. Lyzogubov, P.S. Bora, Relationship between the complement system, risk factors and prediction models in age-related macular degeneration, Mol. Immunol, 63 (2015) 176-183.

[41] K.M. Loyet, J. Good, T. Davancaze, L. Sturgeon, X. Wang, J. Yang, K.N. Le, M. Wong, P.E. Hass, C.M. van Lookeren, P.C. Haughney, A. Morimoto, L.A. mico-Beyer, L.E. DeForge, Complement inhibition in cynomolgus monkeys by anti-factor $\mathrm{d}$ antigen-binding fragment for the treatment of an advanced form of dry age-related macular degeneration, J. Pharmacol. Exp. Ther, 351 (2014) 527-537.

[42] D.V. Do, D.J. Pieramici, C.M. van Lookeren, T. Beres, M. Friesenhahn, Y. Zhang, E.C. Strauss, A phase ia dose-escalation study of the anti-factor D monoclonal antibody fragment FCFD4514S in patients with geographic atrophy, Retina, 34 (2014) 313-320.

[43] Z. Yehoshua, d.A.G.F. CA, R.P. Nunes, G. Gregori, F.M. Penha, A.A. Moshfeghi, K. Zhang, S. Sadda, W. Feuer, P.J. Rosenfeld, Systemic complement inhibition with eculizumab for geographic atrophy in age-related macular degeneration: the COMPLETE study, Ophthalmology, 121 (2014) 693-701.

[44] C.A. Garcia Filho, Z. Yehoshua, G. Gregori, R.P. Nunes, F.M. Penha, A.A. Moshfeghi, K. Zhang, W. Feuer, P.J. Rosenfeld, Change in drusen volume as a novel clinical trial endpoint for the study of complement inhibition in age-related macular degeneration, Ophthalmic Surg. Lasers Imaging Retina, 45 (2014) 18-31.

[45] A. Klos, E. Wende, K.J. Wareham, P.N. Monk, International Union of Basic and Clinical Pharmacology. [corrected]. LXXXVII. Complement peptide C5a, C4a, and C3a receptors, Pharmacol. Rev, 65 (2013) 500-543.

[46] M.C. Wu, F.H. Brennan, J.P. Lynch, S. Mantovani, S. Phipps, R.A. Wetsel, M.J. Ruitenberg, S.M. Taylor, T.M. Woodruff, The receptor for complement component C3a mediates protection from intestinal ischemia-reperfusion injuries by inhibiting neutrophil mobilization, Proc. Natl. Acad. Sci. U. S. A, 110 (2013) 9439-9444.

[47] S.L. Mueller-Ortiz, J.E. Morales, R.A. Wetsel, The receptor for the complement C3a anaphylatoxin $(\mathrm{C} 3 \mathrm{aR})$ provides host protection against Listeria monocytogenes-induced apoptosis, J. Immunol, 193 (2014) 1278-1289. 
[48] J. Cardone, F.G. Le, P. Vantourout, A. Roberts, A. Fuchs, I. Jackson, T. Suddason, G. Lord, J.P. Atkinson, A. Cope, A. Hayday, C. Kemper, Complement regulator CD46 temporally regulates cytokine production by conventional and unconventional T cells, Nat. Immunol, 11 (2010) 862-871.

[49] M.C. Carroll, D.E. Isenman, Regulation of humoral immunity by complement, Immunity, 37 (2012) 199-207.

[50] P.J. Lachmann, R.A. Smith, Taking complement to the clinic--has the time finally come?, Scand. J. Immunol, 69 (2009) 471-478.

[51] L. Skattum, U. Martensson, A.G. Sjoholm, Hypocomplementaemia caused by C3 nephritic factors (C3 NeF): clinical findings and the coincidence of C3 NeF type II with anti-C1q autoantibodies, J. Intern. Med, 242 (1997) 455-464.

[52] D. Ricklin, J.D. Lambris, Therapeutic control of complement activation at the level of the central component C3, Immunobiology, (2015).

[53] A. Sahu, B.K. Kay, J.D. Lambris, Inhibition of human complement by a C3-binding peptide isolated from a phage-displayed random peptide library, J. Immunol, 157 (1996) 884-891.

[54] D.C. Mastellos, D. Yancopoulou, P. Kokkinos, M. Huber-Lang, G. Hajishengallis, A.R. Biglarnia, F. Lupu, B. Nilsson, A.M. Risitano, D. Ricklin, J.D. Lambris, Compstatin: a C3targeted complement inhibitor reaching its prime for bedside intervention, Eur. J. Clin. Invest, 45 (2015) 423-440.

[55] H. Qu, D. Ricklin, H. Bai, H. Chen, E.S. Reis, M. Maciejewski, A. Tzekou, R.A. DeAngelis, R.R. Resuello, F. Lupu, P.N. Barlow, J.D. Lambris, New analogs of the clinical complement inhibitor compstatin with subnanomolar affinity and enhanced pharmacokinetic properties, Immunobiology, 218 (2013) 496-505.

[56] A.M. Risitano, Paroxysmal nocturnal hemoglobinuria and the complement system: recent insights and novel anticomplement strategies, Adv. Exp. Med. Biol, 735 (2013) 155-172.

[57] J. Takeda, T. Miyata, K. Kawagoe, Y. Iida, Y. Endo, T. Fujita, M. Takahashi, T. Kitani, T. Kinoshita, Deficiency of the GPI anchor caused by a somatic mutation of the PIG-A gene in paroxysmal nocturnal hemoglobinuria, Cell, 73 (1993) 703-711.

[58] D.C. Mastellos, D. Ricklin, D. Yancopoulou, A. Risitano, J.D. Lambris, Complement in paroxysmal nocturnal hemoglobinuria: exploiting our current knowledge to improve the treatment landscape, Expert. Rev. Hematol, 7 (2014) 583-598.

[59] R.A. Brodsky, N.S. Young, E. Antonioli, A.M. Risitano, H. Schrezenmeier, J. Schubert, A. Gaya, L. Coyle, C.C. de, C.L. Fu, J.P. Maciejewski, M. Bessler, H.A. Kroon, R.P. Rother, P. Hillmen, Multicenter phase 3 study of the complement inhibitor eculizumab for the treatment of patients with paroxysmal nocturnal hemoglobinuria, Blood, 111 (2008) 1840-1847.

[60] P. Hillmen, P. Muus, U. Duhrsen, A.M. Risitano, J. Schubert, L. Luzzatto, H.

Schrezenmeier, J. Szer, R.A. Brodsky, A. Hill, G. Socie, M. Bessler, S.A. Rollins, L. Bell, R.P. Rother, N.S. Young, Effect of the complement inhibitor eculizumab on thromboembolism in patients with paroxysmal nocturnal hemoglobinuria, Blood, 110 (2007) 4123-4128.

[61] J. Nishimura, M. Yamamoto, S. Hayashi, K. Ohyashiki, K. Ando, A.L. Brodsky, H. Noji, K. Kitamura, T. Eto, T. Takahashi, M. Masuko, T. Matsumoto, Y. Wano, T. Shichishima, H. Shibayama, M. Hase, L. Li, K. Johnson, A. Lazarowski, P. Tamburini, J. Inazawa, T. Kinoshita, Y. Kanakura, Genetic variants in C5 and poor response to eculizumab, N. Engl. J. Med, 370 (2014) 632-639.

[62] T. Rondelli, A.M. Risitano, L.R. Peffault de, M. Sica, B. Peruzzi, P. Ricci, W. Barcellini, A.P. Iori, C. Boschetti, V. Valle, V. Fremeaux-Bacchi, A.M. De, G. Socie, L. Luzzatto, R. 
Notaro, Polymorphism of the complement receptor 1 gene correlates with the hematologic response to eculizumab in patients with paroxysmal nocturnal hemoglobinuria, Haematologica, 99 (2014) 262-266.

[63] A.M. Risitano, R. Notaro, L. Marando, B. Serio, D. Ranaldi, E. Seneca, P. Ricci, F. Alfinito, A. Camera, G. Gianfaldoni, A. Amendola, C. Boschetti, B.E. Di, G. Fratellanza, F. Barbano, F. Rodeghiero, A. Zanella, A.P. Iori, C. Selleri, L. Luzzatto, B. Rotoli, Complement fraction 3 binding on erythrocytes as additional mechanism of disease in paroxysmal nocturnal hemoglobinuria patients treated by eculizumab, Blood, 113 (2009) 4094-4100.

[64] Z. Lin, C.Q. Schmidt, S. Koutsogiannaki, P. Ricci, A.M. Risitano, J.D. Lambris, D. Ricklin, Complement C3dg-mediated erythrophagocytosis: implications for paroxysmal nocturnal hemoglobinuria, Blood, (2015).

[65] A.M. Risitano, R. Notaro, C. Pascariello, M. Sica, V.L. Del, C.J. Horvath, M. FridkisHareli, C. Selleri, M.A. Lindorfer, R.P. Taylor, L. Luzzatto, V.M. Holers, The complement receptor 2/factor $\mathrm{H}$ fusion protein TT30 protects paroxysmal nocturnal hemoglobinuria erythrocytes from complement-mediated hemolysis and C3 fragment, Blood, 119 (2012) 63076316.

[66] C.Q. Schmidt, H. Bai, Z. Lin, A.M. Risitano, P.N. Barlow, D. Ricklin, J.D. Lambris, Rational engineering of a minimized immune inhibitor with unique triple-targeting properties, J. Immunol, 190 (2013) 5712-5721.

[67] A.M. Risitano, D. Ricklin, Y. Huang, E.S. Reis, H. Chen, P. Ricci, Z. Lin, C. Pascariello, M. Raia, M. Sica, V.L. Del, F. Pane, F. Lupu, R. Notaro, R.R. Resuello, R.A. DeAngelis, J.D. Lambris, Peptide inhibitors of C3 activation as a novel strategy of complement inhibition for the treatment of paroxysmal nocturnal hemoglobinuria, Blood, 123 (2014) 2094-2101.

[68] H.F. Weisman, T. Bartow, M.K. Leppo, H.C. Marsh, Jr., G.R. Carson, M.F. Concino, M.P. Boyle, K.H. Roux, M.L. Weisfeldt, D.T. Fearon, Soluble human complement receptor type 1: in vivo inhibitor of complement suppressing post-ischemic myocardial inflammation and necrosis, Science, 249 (1990) 146-151.

[69] J.S. Li, J. Jaggers, P.A. Anderson, The use of TP10, soluble complement receptor 1, in cardiopulmonary bypass, Expert. Rev. Cardiovasc. Ther, 4 (2006) 649-654.

[70] Y. Zhang, C.M. Nester, D.G. Holanda, H.C. Marsh, R.A. Hammond, L.J. Thomas, N.C. Meyer, L.G. Hunsicker, S. Sethi, R.J. Smith, Soluble CR1 therapy improves complement regulation in C3 glomerulopathy, J. Am. Soc. Nephrol, 24 (2013) 1820-1829.

[71] M. Fridkis-Hareli, M. Storek, I. Mazsaroff, A.M. Risitano, A.S. Lundberg, C.J. Horvath, V.M. Holers, Design and development of TT30, a novel C3d-targeted C3/C5 convertase inhibitor for treatment of human complement alternative pathway-mediated diseases, Blood, 118 (2011) 4705-4713.

[72] M.C. Pickering, V.D. D'Agati, C.M. Nester, R.J. Smith, M. Haas, G.B. Appel, C.E. Alpers, I.M. Bajema, C. Bedrosian, M. Braun, M. Doyle, F. Fakhouri, F.C. Fervenza, A.B. Fogo, V. Fremeaux-Bacchi, D.P. Gale, J.E. Goicoechea de, G. Griffin, C.L. Harris, V.M. Holers, S. Johnson, P.J. Lavin, N. Medjeral-Thomas, M.B. Paul, C.C. Nast, L.H. Noel, D.K. Peters, C.S. Rodriguez de, A. Servais, S. Sethi, W.C. Song, P. Tamburini, J.M. Thurman, M. Zavros, H.T. Cook, C3 glomerulopathy: consensus report, Kidney Int, 84 (2013) 1079-1089.

[73] S. Sethi, F.C. Fervenza, Y. Zhang, L. Zand, J.A. Vrana, S.H. Nasr, J.D. Theis, A. Dogan, R.J. Smith, C3 glomerulonephritis: clinicopathological findings, complement abnormalities, glomerular proteomic profile, treatment, and follow-up, Kidney Int, 82 (2012) 465-473. 
[74] A. Servais, L.H. Noel, L.T. Roumenina, Q.M. Le, S. Ngo, M.A. Dragon-Durey, M.A. Macher, J. Zuber, A. Karras, F. Provot, B. Moulin, J.P. Grunfeld, P. Niaudet, P. Lesavre, V. Fremeaux-Bacchi, Acquired and genetic complement abnormalities play a critical role in dense deposit disease and other C3 glomerulopathies, Kidney Int, 82 (2012) 454-464.

[75] A.S. Bomback, Eculizumab in the treatment of membranoproliferative glomerulonephritis, Nephron Clin. Pract, 128 (2014) 270-276.

[76] A.S. Bomback, R.J. Smith, G.R. Barile, Y. Zhang, E.C. Heher, L. Herlitz, M.B. Stokes, G.S. Markowitz, V.D. D'Agati, P.A. Canetta, J. Radhakrishnan, G.B. Appel, Eculizumab for dense deposit disease and C3 glomerulonephritis, Clin. J. Am. Soc. Nephrol, 7 (2012) 748-756.

[77] L.C. Herlitz, A.S. Bomback, G.S. Markowitz, M.B. Stokes, R.N. Smith, R.B. Colvin, G.B. Appel, V.D. D'Agati, Pathology after eculizumab in dense deposit disease and C3 GN, J. Am. Soc. Nephrol, 23 (2012) 1229-1237.

[78] Y. Zhang, D. Shao, D. Ricklin, B.M. Hilkin, C.M. Nester, J.D. Lambris, R.J. Smith, Compstatin analog Cp40 inhibits complement dysregulation in vitro in C3 glomerulopathy, Immunobiology, 220 (2015) 993-998.

[79] A. Klos, A.J. Tenner, K.O. Johswich, R.R. Ager, E.S. Reis, J. Kohl, The role of the anaphylatoxins in health and disease, Mol. Immunol, 46 (2009) 2753-2766.

[80] C.M. Legendre, C. Licht, C. Loirat, Eculizumab in atypical hemolytic-uremic syndrome, N Engl J Med, 369 (2013) 1379-1380.

[81] M. Herper, The most expensive drugs in the world., Forbes Magazine, 2010.

[82] A. Barratt-Due, E.B. Thorgersen, J.K. Lindstad, A. Pharo, O. Lissina, J.D. Lambris, M.A. Nunn, T.E. Mollnes, Ornithodoros moubata complement inhibitor is an equally effective C5 inhibitor in pigs and humans, J. Immunol, 187 (2011) 4913-4919.

[83] P. Stromberg, Introducing SOBI002, a samll Affibody-ABD fusion protein targeting complement component C5., Abstract presented at the 7th International Conference on Complement Therapeutics., Aegean Conferences 82. (2014).

[84] A.Y. Borodovsky, K; Sprague, A; Banda, NK; Holers, VM; Vaishnaw, A, Maier, M; Kallanthottathil, R; Charisse, K; Kuchimanchi, S; Manoharan, M; Salant, DJ; Fitzgerald, K; Meyers, R; Sorensen, B., Aln-CC5, an Investigational RNAi Therapeutic Targeting C5 for Complement Inhibition., Blood, 214 (2014).

[85] M.J. Bendewald, D.A. Wetter, X. Li, M.D. Davis, Incidence of dermatomyositis and clinically amyopathic dermatomyositis: a population-based study in Olmsted County, Minnesota, Arch. Dermatol, 146 (2010) 26-30.

[86] L. Fardet, A. Dupuy, M. Gain, A. Kettaneh, P. Cherin, H. Bachelez, L. Dubertret, C. Lebbe, P. Morel, M. Rybojad, Factors associated with underlying malignancy in a retrospective cohort of 121 patients with dermatomyositis, Medicine (Baltimore), 88 (2009) 91-97.

[87] M.C. Dalakas, Immunotherapy of myositis: issues, concerns and future prospects, Nat Rev Rheumatol, 6 (2010) 129-137.

[88] M.C. Dalakas, Therapeutic advances and future prospects in immune-mediated inflammatory myopathies, Ther Adv Neurol Disord, 1 (2008) 157-166.

[89] M.C. Dalakas, Mechanistic effects of IVIg in neuroinflammatory diseases: conclusions based on clinicopathologic correlations, J Clin Immunol, 34 Suppl 1 (2014) S120-126. [90] F.J. Vanoni1, C; Parvex, P; Chizzolini, C; Hofer, M., A difficult case of juvenile dermatomyositis complicated by thrombotic microangiopathy and purtscher-like retinopathy., Pediatric Rheumatology, 12 (2014) 275. 
[91] L. Pandit, N. Asgari, M. Apiwattanakul, J. Palace, F. Paul, M.I. Leite, I. Kleiter, T. Chitnis, G.I.C. Consortium, O. Biorepository for Neuromyelitis, Demographic and clinical features of neuromyelitis optica: A review, Mult Scler, 21 (2015) 845-853.

[92] M.C. Papadopoulos, A.S. Verkman, Aquaporin 4 and neuromyelitis optica, Lancet Neurol, 11 (2012) 535-544.

[93] S. Saadoun, M.C. Papadopoulos, Role of membrane complement regulators in neuromyelitis optica, Mult. Scler, (2015).

[94] S. Jarius, B. Wildemann, AQP4 antibodies in neuromyelitis optica: diagnostic and pathogenetic relevance, Nat Rev Neurol, 6 (2010) 383-392.

[95] S. Saadoun, P. Waters, B.A. Bell, A. Vincent, A.S. Verkman, M.C. Papadopoulos, Intracerebral injection of neuromyelitis optica immunoglobulin $\mathrm{G}$ and human complement produces neuromyelitis optica lesions in mice, Brain, 133 (2010) 349-361.

[96] P. Nytrova, E. Potlukova, D. Kemlink, M. Woodhall, D. Horakova, P. Waters, E. Havrdova, D. Zivorova, A. Vincent, M. Trendelenburg, Complement activation in patients with neuromyelitis optica, J. Neuroimmunol, 274 (2014) 185-191.

[97] M.V. Jones, K. Fox-Talbot, M. Levy, Evidence for classic complement activity in neuromyelitis optica, Clin. Neuropathol, 33 (2014) 251-252.

[98] M.C. Papadopoulos, J.L. Bennett, A.S. Verkman, Treatment of neuromyelitis optica: stateof-the-art and emerging therapies, Nat. Rev. Neurol, 10 (2014) 493-506.

[99] S.J. Pittock, V.A. Lennon, A. McKeon, J. Mandrekar, B.G. Weinshenker, C.F. Lucchinetti, O. O'Toole, D.M. Wingerchuk, Eculizumab in AQP4-IgG-positive relapsing neuromyelitis optica spectrum disorders: an open-label pilot study, Lancet Neurol, 12 (2013) 554-562. [100] D. Grob, N. Brunner, T. Namba, M. Pagala, Lifetime course of myasthenia gravis, Muscle Nerve, 37 (2008) 141-149.

[101] J.C. Ha, D.P. Richman, Myasthenia gravis and related disorders: Pathology and molecular pathogenesis, Biochim. Biophys. Acta, 1852 (2015) 651-657.

[102] J. az-Manera, E. Martinez-Hernandez, L. Querol, R. Klooster, R. Rojas-Garcia, X. SuarezCalvet, J.L. Munoz-Blanco, C. Mazia, K.R. Straasheijm, E. Gallardo, C. Juarez, J.J.

Verschuuren, I. Illa, Long-lasting treatment effect of rituximab in MuSK myasthenia, Neurology, 78 (2012) 189-193.

[103] B. Zhang, J.S. Tzartos, M. Belimezi, S. Ragheb, B. Bealmear, R.A. Lewis, W.C. Xiong, R.P. Lisak, S.J. Tzartos, L. Mei, Autoantibodies to lipoprotein-related protein 4 in patients with double-seronegative myasthenia gravis, Arch. Neurol, 69 (2012) 445-451.

[104] R.P. Lisak, A.I. Levinson, B. Zweiman, M.J. Kornstein, Antibodies to acetylcholine receptor and tetanus toxoid: in vitro synthesis by thymic lymphocytes, J. Immunol, 137 (1986) 1221-1225.

[105] J.P. Sieb, Myasthenia gravis: an update for the clinician, Clin. Exp. Immunol, 175 (2014) 408-418.

[106] L.L. Kusner, H.J. Kaminski, J. Soltys, Effect of complement and its regulation on myasthenia gravis pathogenesis, Expert. Rev. Clin. Immunol, 4 (2008) 43-52.

[107] L.L. Kusner, J.A. Halperin, H.J. Kaminski, Cell surface complement regulators moderate experimental myasthenia gravis pathology, Muscle Nerve, 47 (2013) 33-40.

[108] J.F. Howard, Jr., R.J. Barohn, G.R. Cutter, M. Freimer, V.C. Juel, T. Mozaffar, M.L. Mellion, M.G. Benatar, M.E. Farrugia, J.J. Wang, S.S. Malhotra, J.T. Kissel, A randomized, double-blind, placebo-controlled phase II study of eculizumab in patients with refractory generalized myasthenia gravis, Muscle Nerve, 48 (2013) 76-84. 
[109] B.B. van den, C. Walgaard, J. Drenthen, C. Fokke, B.C. Jacobs, P.A. van Doorn, GuillainBarre syndrome: pathogenesis, diagnosis, treatment and prognosis, Nat. Rev. Neurol, 10 (2014) 469-482.

[110] J.B. Winer, An update in guillain-barre syndrome, Autoimmune. Dis, 2014 (2014) 793024. [111] H.J. Willison, S.K. Halstead, E. Beveridge, F.M. Zitman, K.N. Greenshields, B.P. Morgan, J.J. Plomp, The role of complement and complement regulators in mediating motor nerve terminal injury in murine models of Guillain-Barre syndrome, J. Neuroimmunol, 201-202 (2008) 172-182.

[112] V.H. Lawson, W.D. Arnold, Multifocal motor neuropathy: a review of pathogenesis, diagnosis, and treatment, Neuropsychiatr. Dis. Treat, 10 (2014) 567-576.

[113] J.M. Leger, R. Guimaraes-Costa, F.R. Iancu, The pathogenesis of multifocal motor neuropathy and an update on current management options, Ther. Adv. Neurol. Disord, 8 (2015) 109-122.

[114] N. Yuki, H. Watanabe, T. Nakajima, P.J. Spath, IVIG blocks complement deposition mediated by anti-GM1 antibodies in multifocal motor neuropathy, J. Neurol. Neurosurg. Psychiatry, 82 (2011) 87-91.

[115] A.M. Fitzpatrick, C.A. Mann, S. Barry, K. Brennan, J.R. Overell, H.J. Willison, An open label clinical trial of complement inhibition in multifocal motor neuropathy, J. Peripher. Nerv. Syst, 16 (2011) 84-91.

[116] S.H. Sacks, W. Zhou, The role of complement in the early immune response to transplantation, Nat Rev Immunol, 12 (2012) 431-442.

[117] C.A. Farrar, W. Zhou, T. Lin, S.H. Sacks, Local extravascular pool of C3 is a determinant of postischemic acute renal failure, FASEB J, 20 (2006) 217-226.

[118] J. Damman, M.A. Seelen, C. Moers, M.R. Daha, A. Rahmel, H.G. Leuvenink, A. Paul, J. Pirenne, R.J. Ploeg, Systemic complement activation in deceased donors is associated with acute rejection after renal transplantation in the recipient, Transplantation, 92 (2011) 163-169.

[119] C.A. Farrar, E. Asgari, W.J. Schwaeble, S.H. Sacks, Which pathways trigger the role of complement in ischaemia/reperfusion injury?, Front Immunol, 3 (2012) 341.

[120] W. Zhou, C.A. Farrar, K. Abe, J.R. Pratt, J.E. Marsh, Y. Wang, G.L. Stahl, S.H. Sacks, Predominant role for C5b-9 in renal ischemia/reperfusion injury, J Clin Invest, 105 (2000) 13631371.

[121] B. de Vries, J. Kohl, W.K. Leclercq, T.G. Wolfs, A.A. van Bijnen, P. Heeringa, W.A.

Buurman, Complement factor C5a mediates renal ischemia-reperfusion injury independent from neutrophils, J Immunol, 170 (2003) 3883-3889.

[122] S. Tang, W. Zhou, N.S. Sheerin, R.W. Vaughan, S.H. Sacks, Contribution of renal secreted complement C3 to the circulating pool in humans, J Immunol, 162 (1999) 4336-4341.

[123] W.H. Kwan, D. Hashimoto, E. Paz-Artal, K. Ostrow, M. Greter, H. Raedler, M.E. Medof, M. Merad, P.S. Heeger, Antigen-presenting cell-derived complement modulates graft-versushost disease, J Clin Invest, 122 (2012) 2234-2238.

[124] M.D. Stegall, M.F. Chedid, L.D. Cornell, The role of complement in antibody-mediated rejection in kidney transplantation, Nat Rev Nephrol, 8 (2012) 670-678.

[125] M.C. Carroll, The complement system in B cell regulation, Mol Immunol, 41 (2004) 141146.

[126] M.D. Stegall, T. Diwan, S. Raghavaiah, L.D. Cornell, J. Burns, P.G. Dean, F.G. Cosio, M.J. Gandhi, W. Kremers, J.M. Gloor, Terminal complement inhibition decreases antibody- 
mediated rejection in sensitized renal transplant recipients, Am J Transplant, 11 (2011) 24052413.

[127] J.E. Locke, C.M. Magro, A.L. Singer, D.L. Segev, M. Haas, A.T. Hillel, K.E. King, E. Kraus, L.M. Lees, J.K. Melancon, Z.A. Stewart, D.S. Warren, A.A. Zachary, R.A. Montgomery, The use of antibody to complement protein C5 for salvage treatment of severe antibodymediated rejection, Am J Transplant, 9 (2009) 231-235.

[128] S. Chen Song, S. Zhong, Y. Xiang, J.H. Li, H. Guo, W.Y. Wang, Y.L. Xiong, X.C. Li, S. Chen Shi, X.P. Chen, G. Chen, Complement inhibition enables renal allograft accommodation and long-term engraftment in presensitized nonhuman primates, Am J Transplant, 11 (2011) 2057-2066.

[129] P.N. Monk, A.M. Scola, P. Madala, D.P. Fairlie, Function, structure and therapeutic potential of complement C5a receptors, Br. J. Pharmacol, 152 (2007) 429-448.

[130] T.M. Woodruff, K.S. Nandakumar, F. Tedesco, Inhibiting the C5-C5a receptor axis, Mol. Immunol, 48 (2011) 1631-1642.

[131] C.G. Kallenberg, Key advances in the clinical approach to ANCA-associated vasculitis, Nat. Rev. Rheumatol, 10 (2014) 484-493.

[132] E.F. McKinney, L.C. Willcocks, V. Broecker, K.G. Smith, The immunopathology of ANCA-associated vasculitis, Semin. Immunopathol, 36 (2014) 461-478.

[133] R.J. Falk, R.S. Terrell, L.A. Charles, J.C. Jennette, Anti-neutrophil cytoplasmic autoantibodies induce neutrophils to degranulate and produce oxygen radicals in vitro, Proc.

Natl. Acad. Sci. U. S. A, 87 (1990) 4115-4119.

[134] A. Schreiber, H. Xiao, J.C. Jennette, W. Schneider, F.C. Luft, R. Kettritz, C5a receptor mediates neutrophil activation and ANCA-induced glomerulonephritis, J. Am. Soc. Nephrol, 20 (2009) 289-298.

[135] H. Xiao, A. Schreiber, P. Heeringa, R.J. Falk, J.C. Jennette, Alternative complement pathway in the pathogenesis of disease mediated by anti-neutrophil cytoplasmic autoantibodies, Am. J. Pathol, 170 (2007) 52-64.

[136] G.Q. Xing, M. Chen, G. Liu, P. Heeringa, J.J. Zhang, X. Zheng, E. J, C.G. Kallenberg, M.H. Zhao, Complement activation is involved in renal damage in human antineutrophil cytoplasmic autoantibody associated pauci-immune vasculitis, J. Clin. Immunol, 29 (2009) 282291.

[137] S.J. Gou, J. Yuan, M. Chen, F. Yu, M.H. Zhao, Circulating complement activation in patients with anti-neutrophil cytoplasmic antibody-associated vasculitis, Kidney Int, 83 (2013) 129-137.

[138] J. Hao, L.Q. Meng, P.C. Xu, M. Chen, M.H. Zhao, p38MAPK, ERK and PI3K signaling pathways are involved in C5a-primed neutrophils for ANCA-mediated activation, PLoS One, 7 (2012) e38317.

[139] L. Camous, L. Roumenina, S. Bigot, S. Brachemi, V. Fremeaux-Bacchi, P. Lesavre, L. Halbwachs-Mecarelli, Complement alternative pathway acts as a positive feedback amplification of neutrophil activation, Blood, 117 (2011) 1340-1349.

[140] C. Wang, H. Wang, J. Hao, D.Y. Chang, M.H. Zhao, M. Chen, Involvement of high mobility group box 1 in the activation of C5a-primed neutrophils induced by ANCA, Clin Immunol, 159 (2015) 47-57. 


\section{Figure Legends}

Figure 1. Complement acts as a key mediator of several pathophysiological processes.

Figure 2. Simplified scheme of the complement cascade. In blue: proteins of the classical and lectins pathways; green: convertases of the classical and lectins pathways; orange: proteins of the alternative pathway; purple: convertases of the alternative pathway; red: proteins common to all the pathways; gray: soluble regulators. Complement cell receptors are depicted at the surface of the host cell. Red symbols: points of therapeutic interventions in rare diseases. Abbreviations: C1INH- C1 inhibitor, C4BP- C4b binding protein, CR- complement receptor, DAF- decay accelerating factor, FB- factor B, FD- factor D, FH- factor H, FI- factor I, MAC- membrane attack complex, MBL- mannose binding lectin, MCP- membrane cofactor protein. *ALN-CC5 inhibits C5 expression.

Figure 3. Impact of drug candidates on complement-mediated functions. Abbreviations: APalternative pathway, CP- classical pathway, C5aR- C5a receptor 1, C1-INH- C1 inhibitor, FDfactor D, FH- factor H, LP- lectin pathway, MAC- membrane attack complex, MASP-2mannose binding lectin. Dotted lines indicate impact in the complement functions downstream of C3 due to less generation of C3b. Full lines indicate impact on C5-mediated functions due to inhibited amplification loop. 
Table 1. List of complement-related drugs with orphan status by the FDA and EMEA.

\begin{tabular}{|c|c|c|c|c|c|}
\hline Compound Name & Manufacturer & $\begin{array}{l}\text { Complement } \\
\text { Target }\end{array}$ & $\begin{array}{l}\text { Designation } \\
\text { Date }\end{array}$ & $\begin{array}{l}\text { Orphan Drug } \\
\text { Status }\end{array}$ & Indication \\
\hline $\begin{array}{c}\text { Berinert } \\
\text { Human C1 esterase inhibitor }\end{array}$ & CSL Behring & $\begin{array}{l}\text { C1r, C1s, MASP-1, } \\
\text { MASP-2, other } \\
\text { proteases }\end{array}$ & 10/16/1992- FDA & Approved & $\begin{array}{l}\text { Prevention and/or treatment of acute } \\
\text { attacks of HAE- Marketed }\end{array}$ \\
\hline Human C1 esterase inhibitor & $\begin{array}{l}\text { Alpha Therapeutic } \\
\text { Corporation } \\
\text { (now Grifols) }\end{array}$ & $\begin{array}{l}\text { C1r, C1s, MASP-1, } \\
\text { MASP-2, other } \\
\text { proteases }\end{array}$ & 8/21/1996- FDA & Designated & $\begin{array}{c}\text { Treatment and prevention of HAE caused by C1- } \\
\text { esterase inhibitor deficiency- Undisclosed } \\
\text { development stage }\end{array}$ \\
\hline $\begin{array}{l}\text { Ruconest } \\
\text { Recombinant C1 esterase inhibitor }\end{array}$ & $\begin{array}{l}\text { Pharming Group N.V. } \\
\text { Licenced by } \\
\text { Santarus/Salix }\end{array}$ & $\begin{array}{l}\text { C1r, C1s, MASP-1, } \\
\text { MASP-2, other } \\
\text { proteases }\end{array}$ & 2/23/1999- FDA & Approved & $\begin{array}{c}\text { Treatment of (acute attacks of) HAE caused by } \\
\text { hereditary or acquired C1-esterase inhibitor } \\
\text { deficiency- Marketed }\end{array}$ \\
\hline $\begin{array}{c}\text { Cinryze } \\
\text { Human C1 esterase inhibitor }\end{array}$ & $\begin{array}{l}\text { ViroPharma Biologics } \\
\text { Incorporated } \\
\text { (now Shire) }\end{array}$ & $\begin{array}{l}\text { C1r, C1s, MASP-1, } \\
\text { MASP-2, other } \\
\text { proteases }\end{array}$ & 7/16/2004- FDA & Approved & $\begin{array}{l}\text { Routine prophylaxis against angioedema attacks } \\
\text { in patients with HAE- Marketed }\end{array}$ \\
\hline $\begin{array}{c}\text { Ruconest } \\
\text { Recombinant human C1 esterase inhibitor }\end{array}$ & Pharming Group N.V. & $\begin{array}{l}\text { C1r, C1s, MASP-1, } \\
\text { MASP-2, other } \\
\text { proteases }\end{array}$ & 6/9/2006- FDA & Designated & $\begin{array}{l}\text { Prevention and/or treatment of delayed graft } \\
\text { function after solid organ transplantation- } \\
\text { Phase I }\end{array}$ \\
\hline $\begin{array}{c}\text { Ruconest } \\
\text { Recombinant human C1 esterase inhibitor }\end{array}$ & Pharming Group N.V. & $\begin{array}{l}\text { C1r, C1s, MASP-1, } \\
\text { MASP-2, other } \\
\text { proteases }\end{array}$ & 6/9/2006- FDA & Designated & $\begin{array}{l}\text { Treatment of capillary leakage syndrome- } \\
\text { Undisclosed development stage }\end{array}$ \\
\hline $\begin{array}{c}\text { OMS721 } \\
\text { Anti human MASP-2 monoclonal antibody }\end{array}$ & Omeros Corporation & MASP-2 & 12/16/2013- FDA & Designated & $\begin{array}{l}\text { Prevention of complement-mediated } \\
\text { thrombotic microangiopathy- Phase II }\end{array}$ \\
\hline $\begin{array}{c}\text { APL-2 } \\
\text { C3-inhibiting peptide (Pegylated) }\end{array}$ & $\begin{array}{c}\text { Apellis } \\
\text { Pharmaceuticals }\end{array}$ & C3 & 4/20/2014- FDA & Designated & Treatment of PNH- Phase I \\
\hline $\begin{array}{l}\text { AMY-101 } \\
\text { C3-inhibiting peptide }\end{array}$ & $\begin{array}{c}\text { Amyndas } \\
\text { Pharmaceuticals }\end{array}$ & C3 & $\begin{array}{l}\text { 10/9/2014- FDA } \\
\text { 10/22/2014- } \\
\text { EMEA }\end{array}$ & Designated & Treatment of PNH- Pre-clinical \\
\hline $\begin{array}{l}\text { TP10 (CDX-1135) } \\
\text { Soluble complement receptor type } 1\end{array}$ & $\begin{array}{l}\text { Avant } \\
\text { Immunotherapeutics } \\
\text { (now Celldex) }\end{array}$ & $\begin{array}{l}\text { C3-convertase, } \\
\text { C4b, C3b }\end{array}$ & 3/6/2000- FDA & Designated & $\begin{array}{l}\text { Prevention of post-cardiopulmonary bypass } \\
\text { syndrome in children undergoing } \\
\text { cardiopulmonary bypass- Phase II }\end{array}$ \\
\hline $\begin{array}{l}\text { Mubodina } \\
\text { Recombinant human minibody } \\
\text { against component C5 }\end{array}$ & Adienne S.A. & C5 & $\begin{array}{l}\text { 2/4/2009- FDA } \\
\text { 10/27/2011- } \\
\text { EMEA }\end{array}$ & Designated & $\begin{array}{c}\text { Treatment of primary membranoproliferative } \\
\text { glomerulonephritis- } \\
\text { Pre-clinical }\end{array}$ \\
\hline $\begin{array}{l}\text { Mubodina } \\
\text { Recombinant human minibody } \\
\text { against component C5 }\end{array}$ & Adienne S.A & C5 & 6/7/2011- FDA & Designated & $\begin{array}{c}\text { Treatment of aHUS associated with an inherited } \\
\text { abnormality of the complement system- } \\
\text { Pre-clinical }\end{array}$ \\
\hline
\end{tabular}




\begin{tabular}{|c|c|c|c|c|c|}
\hline Compound Name & Manufacturer & $\begin{array}{l}\text { Complement } \\
\text { Target }\end{array}$ & Designation Date & $\begin{array}{l}\text { Orphan Drug } \\
\text { Status }\end{array}$ & Indication \\
\hline $\begin{array}{c}\text { Ergidina } \\
\text { Recombinant human minibody against } \\
\text { component C5 fused with RGD-motif }\end{array}$ & Adienne S.A. & $\mathrm{C5}$ & 2/4/2009- FDA & Designated & $\begin{array}{c}\text { Prevention of ischemia/reperfusion injury } \\
\text { associated w ith solid organ transplantation- } \\
\text { Pre-clinical }\end{array}$ \\
\hline Eculizumab & Alexion Pharmaceuticals & C5 & $9 / 21 / 2000$ & Designated & $\begin{array}{l}\text { Treatment of dermatomyositis- } \\
\text { Phase II }\end{array}$ \\
\hline Eculizumab & Alexion Pharmaceuticals & C5 & 3/5/2001- FDA & Designated & $\begin{array}{l}\text { Treatment of idiopathic membranous } \\
\text { glomerular nephropathy- Phase ॥ }\end{array}$ \\
\hline Eculizumab & Alexion Pharmaceuticals & C5 & $\begin{array}{l}\text { 8/20/2003- FDA } \\
\text { 10/17/2003- EMEA }\end{array}$ & $\begin{array}{l}\text { Designated/ } \\
\text { Approved }\end{array}$ & Treatment of PNH- Marketed \\
\hline Eculizumab & Alexion Pharmaceuticals & C5 & $\begin{array}{l}\text { 4/29/2009- FDA } \\
\text { 7/24/2009- EMEA }\end{array}$ & $\begin{array}{l}\text { Designated/ } \\
\text { Approved }\end{array}$ & Treatment of aHUS- Marketed \\
\hline Eculizumab & Alexion Pharmaceuticals & C5 & $\begin{array}{l}\text { 10/18/2011- FDA } \\
\text { 4/7/2012- EMEA }\end{array}$ & $\begin{array}{l}\text { Designated/ } \\
\text { Approved }\end{array}$ & $\begin{array}{c}\text { Treatment of infection-associated hemolytic } \\
\text { uraemic syndrome- Phase I/III }\end{array}$ \\
\hline Eculizumab & Alexion Pharmaceuticals & C5 & $\begin{array}{l}\text { 6/24/2013- FDA } \\
\text { 5/8/2013- EMEA }\end{array}$ & Designated & $\begin{array}{c}\text { Treatment of neuromyelitis optica- } \\
\text { Phase III }\end{array}$ \\
\hline Eculizumab & Alexion Pharmaceuticals & C5 & $\begin{array}{l}\text { 1/10/2014- FDA } \\
\text { 2/19/2014- EMEA }\end{array}$ & Designated & $\begin{array}{l}\text { Prevention of delayed graft function after solid } \\
\text { organ transplantation- Phase ॥ }\end{array}$ \\
\hline Eculizumab & Alexion Pharmaceuticals & C5 & 3/26/2014- EMEA & Designated & $\begin{array}{c}\text { Prevention of graft rejection following solid organ } \\
\text { transplantation- Phase ॥ }\end{array}$ \\
\hline Eculizumab & Alexion Pharmaceuticals & C5 & $\begin{array}{l}\text { 6/13/2014- FDA } \\
\text { 7/29/2014- EMEA }\end{array}$ & Designated & $\begin{array}{c}\text { Treatment of myasthenia gravis- } \\
\text { Phase III }\end{array}$ \\
\hline $\begin{array}{c}\text { CCX168 } \\
\text { C5aR Antagonist }\end{array}$ & ChemoCentryx & $\mathrm{C} 5 \mathrm{aR}$ & 6/2/2014- FDA & Designated & $\begin{array}{l}\text { ANCA-associated vasculitis- } \\
\text { Phase II }\end{array}$ \\
\hline $\begin{array}{c}\text { CCX168 } \\
\text { C5aR Antagonist }\end{array}$ & ChemoCentryx & $\mathrm{C} 5 \mathrm{aR}$ & 11/17/2014- FDA & Designated & $\begin{array}{l}\text { Treatment of aHUS associated with an inherited } \\
\text { abnormality of the complement system- Phase ॥ }\end{array}$ \\
\hline
\end{tabular}

Abbreviations: aHUS- atypical hemolytic uremic syndrome, ANCA- anti-neutrophil cytoplasmic antibody, C5aR1- C5a receptor, EMEAEuropean Medicines Agency, FDA- Food and Drug Administration, HAE-hereditary angioedema, MASP- MBL-associated serine protease, PNH-paroxysmal nocturnal hemoglobinuria. 
Table 2. List of complement-related drugs without orphan designation in pre-clinical and clinical development for rare diseases.

\begin{tabular}{|c|c|c|c|}
\hline Compound Name & Manufacturer & Complement Target & Indication \\
\hline $\begin{array}{c}\text { Cetor } \\
\text { C1 esterase inhibitor }\end{array}$ & Sanquin & $\begin{array}{c}\text { C1r, C1s, MASP-1, } \\
\text { MASP-2, other proteases }\end{array}$ & $\begin{array}{c}\text { Hereditary Angioedema, } \\
\text { Acquired C1-inhibitor deficiency }\end{array}$ \\
\hline $\begin{array}{c}\text { TNT009 } \\
\text { Anti-C1s Antibody }\end{array}$ & True North Therapeutics & C1s & $\begin{array}{c}\text { Cold Agglutinin Disease } \\
\text { Phase I }\end{array}$ \\
\hline $\begin{array}{l}\quad \text { Lampalizumab } \\
\text { Anti-Factor D Antibody } \\
\text { (FCFD4514S, RG7417) }\end{array}$ & Genentech & FD & $\begin{array}{c}\text { Age-related Macular Degeneration } \\
\text { Phase I/III }\end{array}$ \\
\hline $\begin{array}{c}\text { ACH-CFDIS } \\
\text { Anti-Factor D inhibitor }\end{array}$ & Achillion & FD & Pre-clinical \\
\hline $\begin{array}{c}\text { CDX-1135 (TP10) } \\
\text { soluble CR1 }\end{array}$ & Celldex & $\begin{array}{l}\text { C3-convertase, } \\
\text { C4b, C3b }\end{array}$ & $\begin{array}{c}\text { Dense Deposit Disease } \\
\text { Phase I }\end{array}$ \\
\hline $\begin{array}{c}\text { TT30 } \\
\text { (ALXN1102) }\end{array}$ & Alexion Pharmaceuticals & C3-convertase, C3b & $\begin{array}{c}\text { Paroxysmal Nocturnal Hemoglobinuria } \\
\text { Phase I }\end{array}$ \\
\hline тт32 & Alexion Pharmaceuticals & C3-convertase, C4b, C3b & Pre-clinical \\
\hline Mini-FH & Amyndas & C3-convertase, C3b & $\begin{array}{l}\text { Paroxysmal Nocturnal Hemoglobinuria } \\
\text { Pre-clinical }\end{array}$ \\
\hline $\begin{array}{c}\text { Zimura } \\
\text { (ARC1905) }\end{array}$ & Ophthotech & $\mathrm{C} 5$ & $\begin{array}{c}\text { Age-related Macular Degeneration } \\
\text { Phase II }\end{array}$ \\
\hline LFG316 & Novartis & C5 & $\begin{array}{c}\text { Dry Age-related Macular Degeneration } \\
\text { Phase II }\end{array}$ \\
\hline $\begin{array}{l}\text { Coversin } \\
\text { (OmCl) }\end{array}$ & $\begin{array}{l}\text { Volution Immuno- } \\
\text { Pharmaceuticals }\end{array}$ & C5 & $\begin{array}{c}\text { Age-related Macular Degeneration } \\
\text { Phase I }\end{array}$ \\
\hline SOBI002 & Sw edish Orphan Biovitrum & C5 & Phase I \\
\hline RA101348 & Ra Pharmaceuticals & C5 & Pre-clinical \\
\hline $\begin{array}{c}\text { ALN-CC5 } \\
\text { (Anti-C5 siRNA) }\end{array}$ & Alnylam & C5 & $\begin{array}{c}\text { Paroxysmal Nocturnal Hemoglobinuria } \\
\text { Phase VIII }\end{array}$ \\
\hline $\begin{array}{l}\mathrm{CaCP} 29 \\
(\mathrm{IFX}-1)\end{array}$ & InflaRx & $\mathrm{C} 5 \mathrm{a}$ & $\begin{array}{l}\text { Sepsis } \\
\text { Phase II }\end{array}$ \\
\hline
\end{tabular}




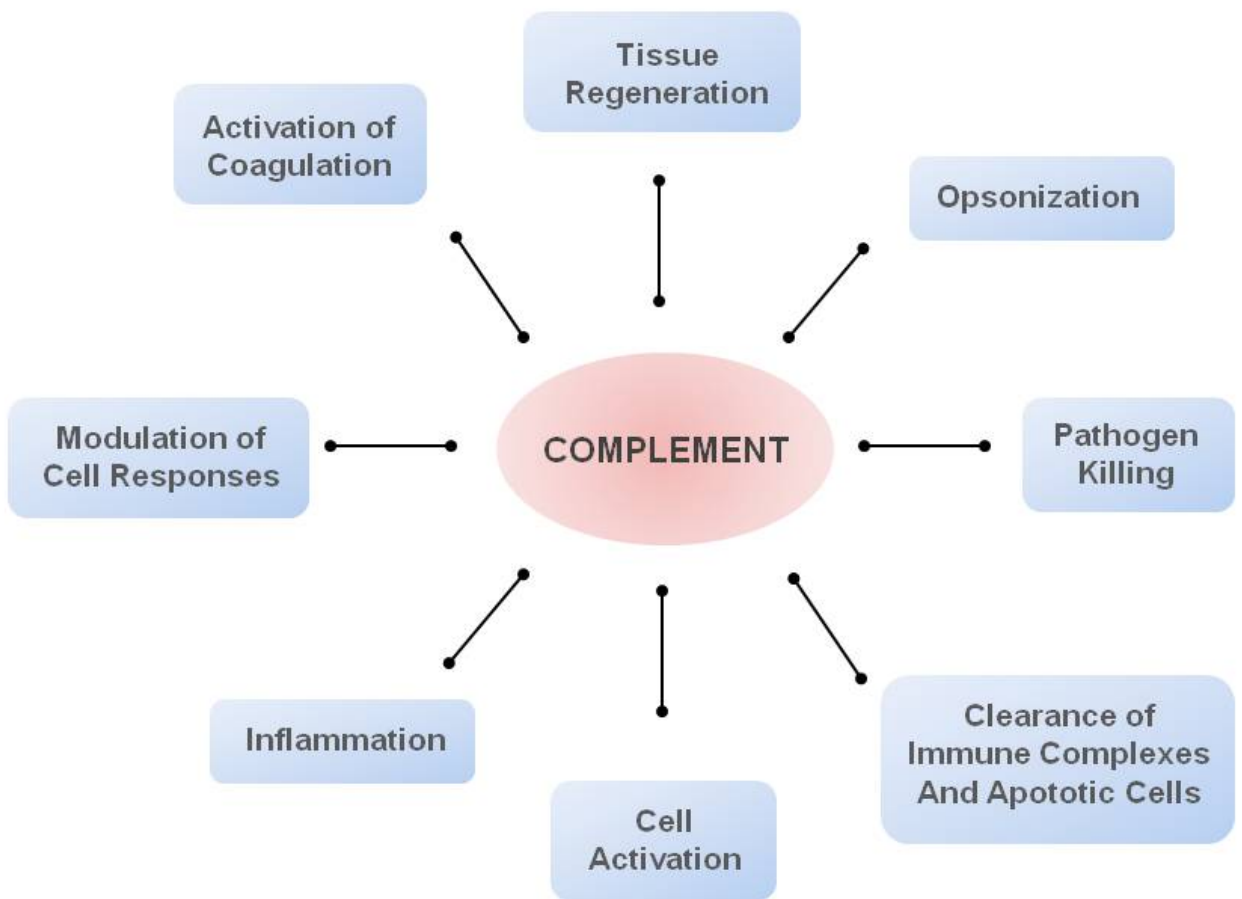

Figure 1 
CLASSICAL PATHWAY
LECTINS

PATHWAY
ALTERNATIVE

PATHWAY

PATHOGENS AND DAMAGED CELLS

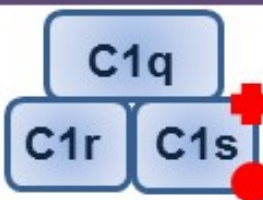

CIIHN

C4BP
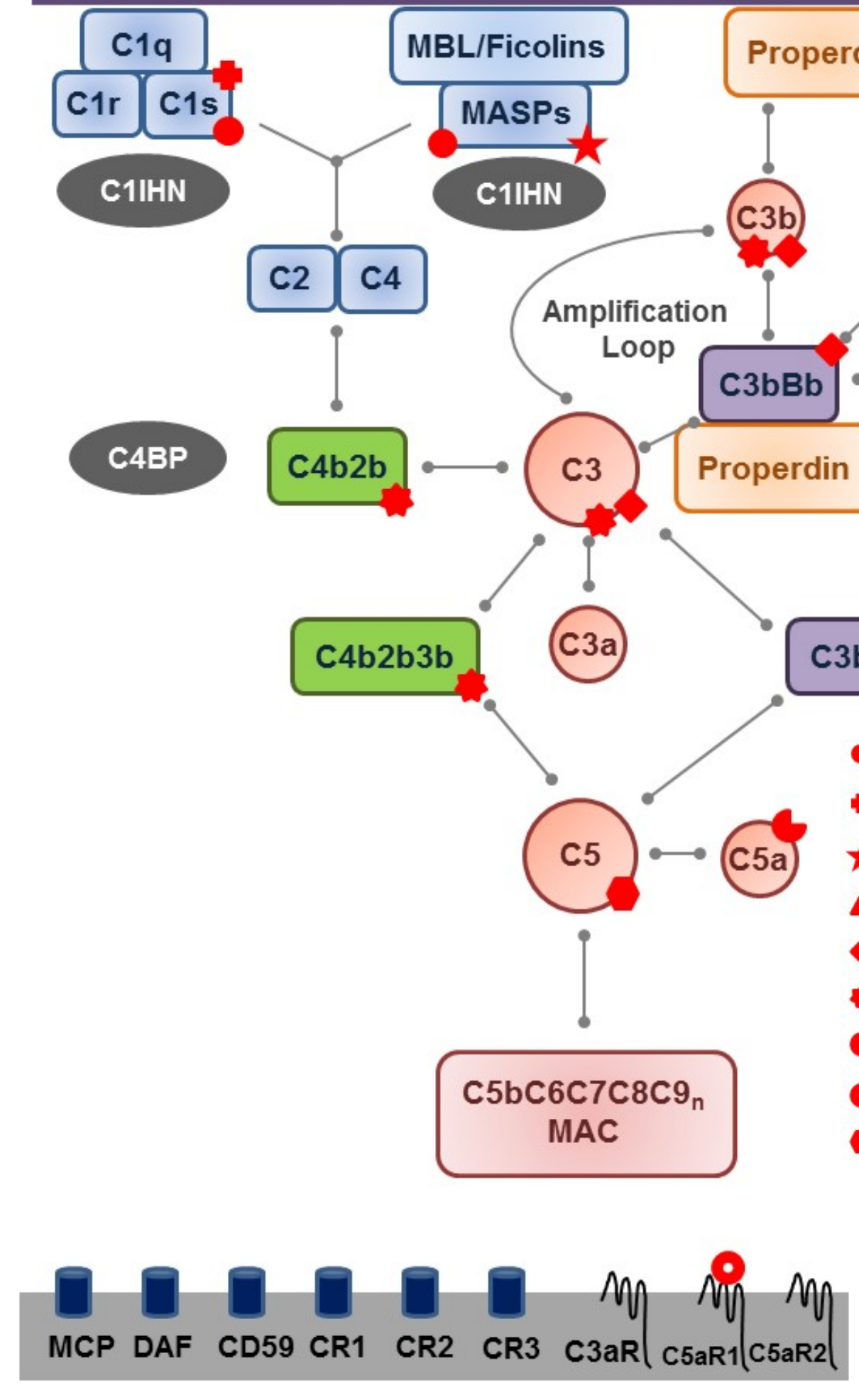

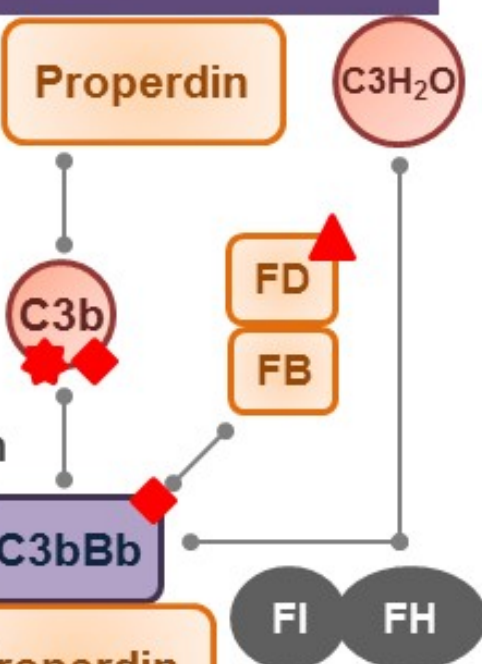

Properdin

HOST CELL

Figure 2 


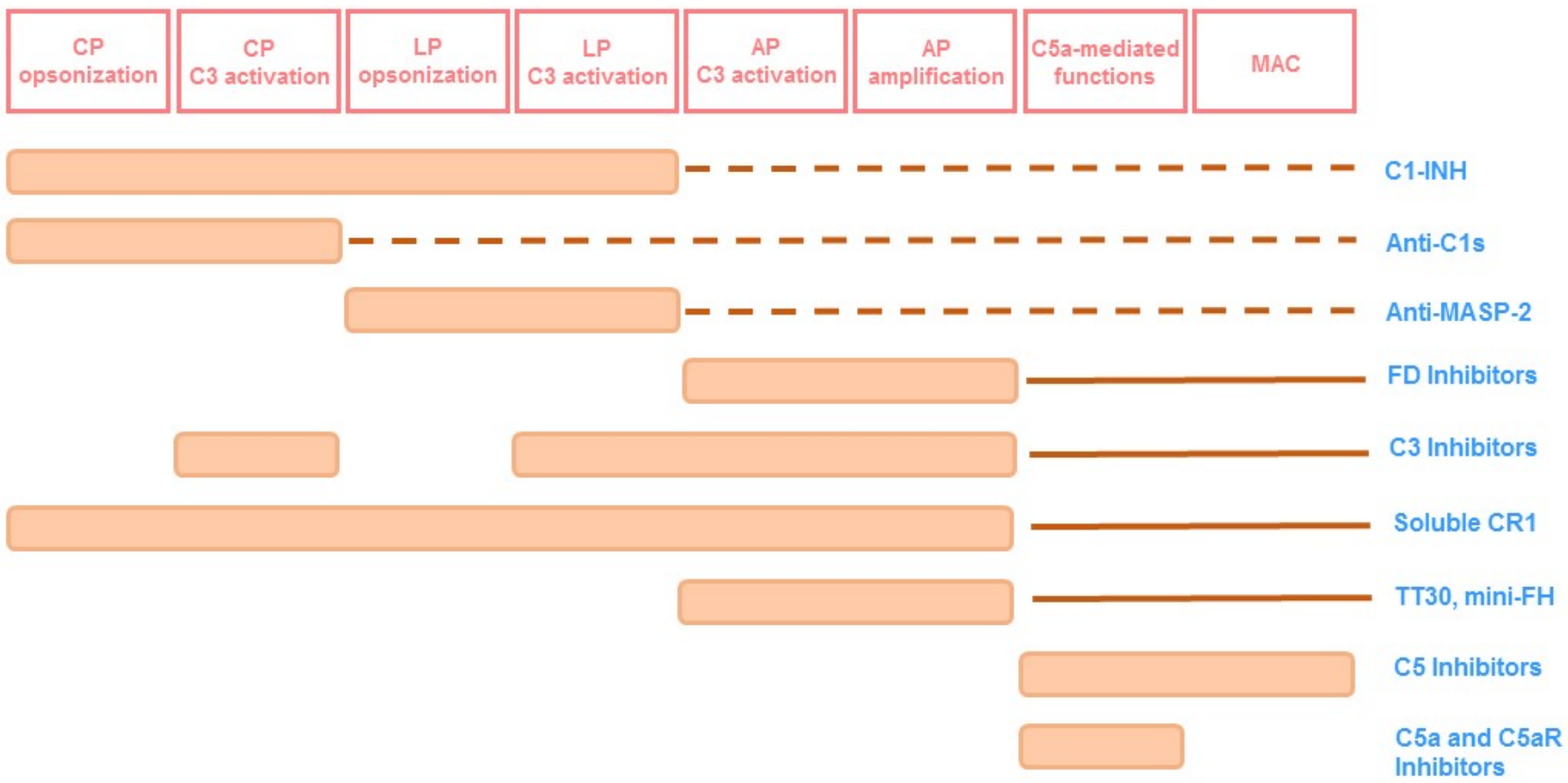

Figure 3 